Alma Mater Studiorum - Università di Bologna DEPARTMENT OF ECONOMICS

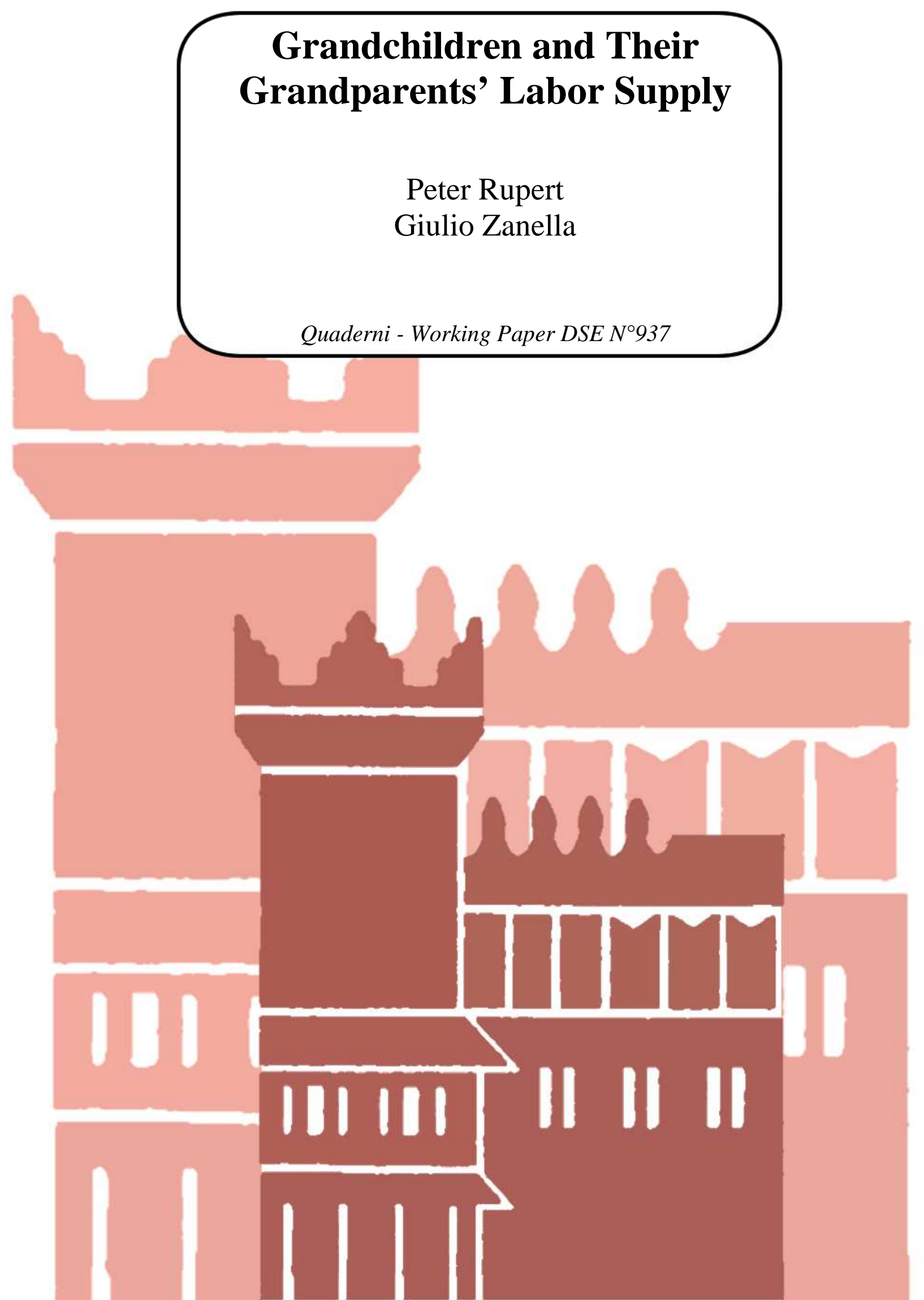




\title{
Grandchildren and Their Grandparents' Labor Supply*
}

\author{
Peter Rupert \\ $\mathrm{UCSB}^{\dagger}$
}

\author{
Giulio Zanella \\ University of Bologna
}

February 28, 2014

\begin{abstract}
We study how becoming a grandparent affects grandparents' labor supply. In a simple model of the allocation of time in which seniors care about their offspring's welfare and also value time spent with family children, the sign of the effect is ambiguous. Using data from the Panel Study of Income Dynamics we find evidence that becoming a grandparent causes a reduction of employed grandmother's hours of work. We identify a lower bound of about 190. This effect originates towards the bottom of the hours distribution (i.e., among women less attached to the labor market). For employed grandfathers, the effect is also negative, originates towards the top of the hours distribution (i.e., where overtime work is substantial), but is smaller and more imprecisely estimated than for women. We also find that for working grandmothers the effect is stronger the closer grandparents and grandchildren live and during the first years since becoming a grandparent (i.e., when the grandchildren are younger). The "extensive margin" of grandparenting (becoming a grandparent) turns out to be much more important in generating these effects than the corresponding "intensive" margin (having additional grandchildren).
\end{abstract}

JEL Classification Codes: D19, J13, J14, J22.

Keywords: Senior's labor supply, Grandparents, Child care.

${ }^{*}$ We are grateful to Kelly Bedard, Andrea Ichino, John Kennan, Peter Kuhn, and Shelly Lundberg for useful suggestions. All errors are ours.

${ }^{\dagger}$ E-mail: rupert@econ. ucsb.edu.

†Corresponding author. E-mail: giulio.zanella@unibo.it 


\section{Introduction}

The American Community Survey from the U.S. Census Bureau estimates that there are about 70 million grandparents in the U.S., almost 1/3 of the adult American population. The vast majority of these have grandchildren well before reaching the end of working age. Time use data, in turn, show that these individuals make large time transfers in the form of grandparent-provided child care. In the literature, much is known about the labor supply consequences of becoming a parent, something is known about the effect of grandparent-provided child care on parents' labor supply, but very little is known about the effect of grandparent-provided child care on grandparents' own labor supply. This paper addresses this issue and asks: How does becoming a grandparent affect the labor supply of older workers?

We find evidence that becoming a grandparent reduces women's labor supply along the intensive margin; our baseline estimates indicate a lower bound of about 190 hours per year. The point estimate for men is lower, a reduction of about 70 hours per year, although with a large standard error and a possible upward bias. This asymmetric effect is consistent with the different responsiveness of men and women to changes in the opportunity cost of time, as has been documented repeatedly in the literature on labor supply elasticities. Going beyond this baseline estimate, we find that these labor supply adjustments by women take place at the lower quantiles of the hours distribution; for men, on the contrary, they (if any) take place at the upper quantiles. Moreover, as one would expect, distance between grandparents and the grandchild also matters. For women, the reduction in hours of work increases with proximity to grandchildren, roughly (in lower bound) an additional 100 hours if living in the same county and 130 if living in the same census tract. However, it appears that for men the entire effect is driven by those living far away from the grandchildren, but again with large standard errors. We also find evidence that the effect is stronger the more recently one became a grandparent (i.e., when one's grandchildren are younger) and the older one is. Finally, we find that becoming a grandparent (i.e., the "extensive margin" of grandparenting) is much more important in generating these effects than having additional grandchildren (i.e., the "intensive" margin of grandparenting).

These non-negligible labor supply effects of becoming a grandparent are not surprising given the picture emerging from the data on informal child care arrangements and time use. According to the U.S. Census Bureau (Survey of Income and Program Participation) in 2011 as many as 23.4\% of all children under 5 years old living with their mother benefited from grandparent-provided child care (between 5 and 14 years it is 13.4\%), up from less than 15\% in 1987. For $93 \%$ of these, grandparents were the primary child care arrangement. These statistics do not include children living with their grandparents, which according to the U.S. Census Bureau amounted to about 7\% of all children below 18 years old in 2010, up from 3.2\% in 1970.

Correspondingly, time use data show that beginning around age 50, as parents become grandparents and, presumably, own children no longer need adult care, primary child care time does not drop to zero, and actually increases for those who report a strictly positive amount of time spent taking care of children. Figure 1 documents this fact by showing the average daily minutes spent in primary child care, both unconditionally (i.e., including those who report zero minutes) and conditional on reporting a strictly positive amount of minutes in the pooled 2008-2012 cross-section of the American Time Use Survey (ATUS). ${ }^{1}$

\footnotetext{
${ }^{1}$ Before age 50, $44 \%$ of women and $26 \%$ of men in this ATUS sample report spending a strictly positive amount
} 
These data are consistent with information from the Health and Retirement Study (HRS). In the HRS, individuals are asked how much time they spent taking care of their grandchildren during the past 12 months. Individuals in the HRS subsample were between 51 and 61 years old at the time of the first interview in 1992. In that year, grandmothers who did at least one hour of grandchild care reported spending, on average, about 820 hours taking care of their grandchildren. The corresponding figure for grandfathers was about 440 hours. These statistics from the HRS are in accordance with those from the ATUS, and are equivalent to about 21 and 11 workweeks, respectively. Such large time transfers beg the question of how much grandparenting comes at the expense of other forms of "leisure" and how much comes at the expense of market labor supply? This is the central question of the paper.

Figure 1: Primary child care time by age, 2008-2012

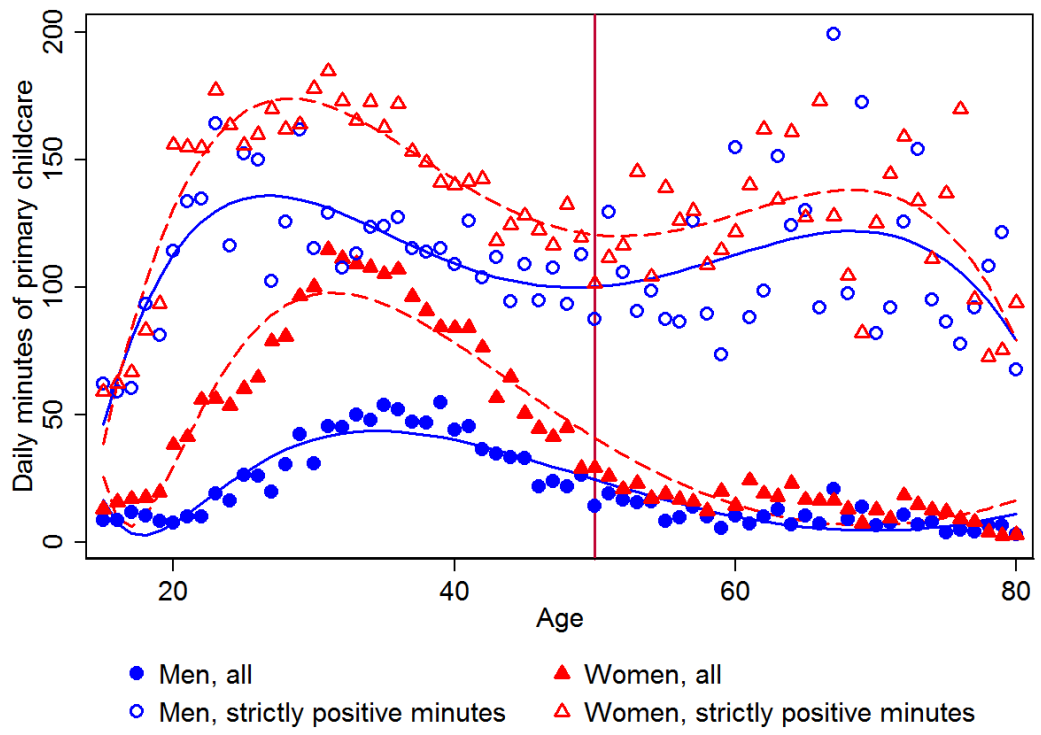

Notes: Average daily minutes of primary child care (caring for and helping, and activities related to children's education and health), and associated travel, by gender of the caregiver, in the pooled 2008-2012 cross sections of the American Time Use Survey, by age of the respondent. Both children living in the household and those living in another household are considered. The interpolating line is the best fourth order fractional polynomial. Individual sampling weights are applied.

There is surprisingly little evidence on this point. A substantial body of quasi-experimental evidence has accumulated over the past 20 years about the causal effect of child bearing on parental labor supply. ${ }^{2}$ Virtually all studies find a negative effect using a variety of instruments to address the endogeneity of fertility, such as twin births (Bronars and Grogger (1994) for unmarried mothers in the US, and Jacobsen, Pearce, and Rosenbloom (1999) for married mothers) ${ }^{3}$, sibling-sex composition (Angrist and Evans (1998) for men and women in the US, and Cruces and Galiani (2007)

of minutes taking care of children. After age 50 these drop to $13 \%$ and $10 \%$, respectively. The activities included are caring for and helping, activities related to children's education and health, and travel related to all of these.

2 Studies providing indirect evidence of this connection via the evaluation of public child care programs on women's labor supply have a long tradition in modern labor economics, starting with Heckman (1974).

3 The idea of using twin births as an exogenous shock to fertility traces back to Rosenzweig and Wolpin (1980). 
for women in Argentina and Mexico), gender of first-born child (Chun and Oh (2002) for women in South Korea) early access to the pill (Bailey (2006) for women in the US), abortion legislation (Bloom, Canning, Fink, and Finlay (2009) in a large cross-country panel data set). ${ }^{4}$ More recently, researchers have begun investigating the effect of grandparents-provided child care on parental labor supply. By providing free and flexible child care, grandparents may reduce the impact of child bearing on parents' labor supply. In an early paper, Cardia and $\mathrm{Ng}$ (2003) calibrate an OLG model and show that grandparent-provided childcare has a positive effect on the labor supply of parents. In an empirical counterpart of this calibration study, Dimova and Wolff (2011) use cross-country data from the Survey of Health, Aging, and Retirement in Europe (SHARE) show that this is the case for young European mothers. Posadas and Vidal-Fernandez (2012) instrument the availability of grandparents-provided child care with death of the maternal grandmother in the National Longitudinal Survey of Youth 1979 (NLSY79), and find that the availability of grandparents increases the labor force participation of mothers in the U.S. Compton and Pollak (2014) employ data from the U.S. Census and from the National Survey of Families and Households (NSFH), and show that spatial proximity to grandmothers increases the labor supply of women with young children, presumably because of the availability of grandparent-provided child care. ${ }^{5}$

However, very little is known about the effect of grandparent-provided child care on grandparents' own labor supply. Existing studies of the link between grandparenting and grandparents' labor supply are descriptive in nature (i.e., do not address causality), and report mixed correlations. Lei (2008) uses HRS data from 1996 to 2002, and finds a small positive correlation between the number of grandchildren and grandmother's labor supply along both the intensive and the extensive margin. However, when including fixed effects the correlation becomes negative and insignificant. Ho (2014) also uses HRS data and finds a positive correlation between the birth of a new grandchild and married grandparents' employment. She also finds a positive correlation between married grandmothers' hours of market work and the presence of a grandchild in the household. Zamarro (2011) estimates on SHARE data the effect of being an employed grandmother on the probability of providing child care. Instrumenting employment status with eligibility for social security benefits, and finds a negative effect.

We take a systematic approach to this question using data from the Panel Study of Income Dynamics (PSID) to estimate the effect of becoming a grandparent on grandparents' (men and women) labor supply (participation and hours), addressing the endogeneity of the grandparent status. The PSID, as of 2013, spans 44 years and is especially well-suited for this research question. Its genealogical design offers us the opportunity to link grandparents, parents, and grandchildren for an extended period of time and for different cohorts, while observing the characteristics of all three generations. Moreover, the longitudinal span of this survey allows us to observe the same individuals both when they become parents and, many years later, when they become grandparents.

Although becoming a grandparent, unlike becoming a parent, results from the fertility choices of someone else, there are at least two sources of endogeneity. First, preferences for fertility may be transmitted from parents to children. Second, the cost of having a child decreases with the expected

\footnotetext{
${ }^{4}$ However, when using self-reported measures of infertility as instruments, both Aguero and Marks (2008) in a sample of Latin American countries, and Rondinelli and Zizza (2010) in sample of older Italian women find no effect of child bearing on female labor force participation.

${ }^{5}$ Additional, possible effects of grandparenting not directly related to labor supply have also been explored. Reinkowski (2013) finds some positive correlation in SHARE data between taking care of the grandchildren and grandparents' physical and psychological health.
} 
time transfer a grandparent provides. In the reduced form approach we take in this paper, the first problem can be mitigated by including individual fixed effects, but this is not enough to take care of possible reverse causation in the second problem: one needs an instrument for the probability of becoming a grandparent. Our strategy in this respect is based on the straightforward observation that every valid instrument for one's fertility, conditional on having at least one child, is also a valid instrument for the probability of being a grandparent at any point in life, because such probability increases with the number of own children. There are two such instruments that have been used in the literature that we can also exploit. First, the sibling sex mix. Second, the gender of one's first child. In the context of grandparenting these instruments operate via the additional channel of timing, because girls have children earlier than boys. We show that such a timing channel is more important than the fertility one. ${ }^{6}$ These instruments are not without limitations, which we discuss later in the paper. However, we show that such limitations do not threaten our central results.

The remainder of the paper is organized as follows. Section 2 illustrates the underlying theoretical mechanisms and connects it to the econometrics. Section 3 contains the baseline empirical analysis, Section 4 contains extensions of the baseline results, and Section 5 concludes.

\section{Model}

The model is intentionally simple. Its only purpose is to illustrate in a transparent way the mechanisms relating grandchild care and grandparents' labor supply, as well as the sources of endogeneity of the grandparent status in any empirical analysis of such mechanisms. Because we want to study labor supply late in the working life, we employ a static model of the allocation of time à la Becker (1965).

We consider a population of older individuals (Seniors, henceforth) each with one adult child (Junior, henceforth) whom in turn may or may not produce a grandchild (Baby, henceforth). That is, from the viewpoint of Senior, becoming a grandparent is an uncertain-although possibly not exogenous-event represented by a random variable $g$. If Junior produces Baby, then $g=1$, otherwise, $g=0$. Families are defined along vertical lines: composed of Senior, Junior, and, possibly, Baby. Although the distinction between married and unmarried grandparents is potentially important and a collective model of family labor supply an appropriate framework, here we adopt the basic unitary model. Seniors are altruistic in that they care about Junior's welfare. There are three goods: a composite consumption good, $c$, leisure, $l$, and time spent with family children (i.e., with Baby), $x$. Consumption and leisure are normal goods.

In what follows we adopt the following three notational conventions: (i) a prime, ", ", denotes objects that pertain to Junior; (ii) for derivatives, we adopt the subscript notation, so that $f_{y}$ denotes the partial derivative of function $f$ with respect to variable $y$; (iii) a 0 or 1 subscript denotes the value a variable or function takes at the optimum when $g=0$ and $g=1$, respectively, so that, for instance, $y_{0}$ is $y^{*}(g=0)$ and $f_{1}$ is $f^{*}(g=1)$.

The utility functions of Senior and Junior (Baby has no choices to make in this model) are denoted $U$ and $U^{\prime}$, and represent well-behaved preferences, given by, respectively,

$$
\begin{aligned}
U & =u(c)+v(l)+v(x)+\rho\left[u\left(c^{\prime}\right)+v\left(l^{\prime}\right)+v\left(x^{\prime}\right)\right], \\
U^{\prime} & =u\left(c^{\prime}\right)+v\left(l^{\prime}\right)+v\left(x^{\prime}\right)+\varepsilon(g),
\end{aligned}
$$

\footnotetext{
${ }^{6}$ Another possible instrument is twin births, but there are too few cases in the PSID.
} 
where $\rho$ is the intergenerational altruism parameter and $\varepsilon(g)$ represents Junior's unobserved (to Senior) preference for producing Baby. Notice two things. First, the non-idiosyncratic components of preferences are perfectly transmitted from Senior to Junior. Second, it is necessarily the case that $x_{0}=x_{0}^{\prime}=0$; that is, if Junior does not produce Baby, no one in the family can enjoy time spent with family children.

Senior and Junior are endowed with 1 unit of time, which they can supply to the labor market (these supplies are denoted $h$ and $h^{\prime}$, respectively) at a given wage rate ( $w$ and $w^{\prime}$, respectively), enjoy as leisure, or spend with Baby-if present in the family. That is, the time constraints of Senior and Junior are given by $h+l+x=1$ and $h^{\prime}+l^{\prime}+x^{\prime}=1$, respectively.

Child rearing requires a single input: a fixed amount of time, $\bar{h}$. Child care is also available on the market at price $p$ per unit of time. The market supply is exogenous and perfectly elastic. Therefore, time spent with children is both an input to child rearing and home production of a valuable good (time spent with family children) for which there is no market. We assume that child care time cannot be sold outside the family and that $\bar{h}$ is sufficiently large so that, in equilibrium, $x+$ $x^{\prime} \leq \bar{h}$. The crucial difference between the two generations is that Junior can produce Baby, while Senior can not. Therefore, the only way Senior can enjoy time with children is by supplying time to the child rearing process when Junior produces Baby, i.e., grandparenting. Because child rearing time can be purchased by junior on the market, grandparenting $(x)$ is an intergenerational time transfer. The other form of intergenerational transfer seniors can make is a monetary (consumption) transfer, denoted $t$. We assume there are no commitment problems when Senior chooses $x$ and $t$. The budget constraints of Senior and Junior are given by, respectively,

$$
\begin{aligned}
c+t & =w h \\
c^{\prime}+\left(\bar{h}-x^{\prime}-x\right) p g & =w^{\prime} h^{\prime}+t .
\end{aligned}
$$

We first analyze Junior's decision to produce Baby, from the viewpoint of Senior. The solution is a probability function:

$$
\begin{aligned}
\operatorname{Pr}(g=1) & =\operatorname{Pr}\left(U_{1}^{\prime} \geq U_{0}^{\prime}\right) \\
& =F\left[u\left(w^{\prime} h_{1}^{\prime}-\left(\bar{h}-x^{\prime}-x\right) p\right)-u\left(w^{\prime} h_{0}^{\prime}\right)+v\left(l_{1}^{\prime}\right)-v\left(l_{0}^{\prime}\right)+v\left(x^{\prime}\right)-v(0)\right] .
\end{aligned}
$$

The probability Senior becomes a grandparent depends on her or his time transfer $x$, both directly via Junior's budget constraint and indirectly via the equilibrium levels of $h_{1}^{\prime}, l_{1}^{\prime}$, and $x^{\prime}$. It is easy to see that if $\bar{h}$ is sufficiently large then such probability increases monotonically with $x$. Intuitively, the time transfer from Senior reduces Junior's cost of child bearing. ${ }^{7}$ The key point here is that $g$ and $x$ are simultaneously determined. Such simultaneity highlights the fundamental endogeneity problem one faces in empirical analyses of the effect of becoming a grandparent on labor supply. Another source of endogeneity Eq. 5 makes clear is the intergenerational correlation of preferences: the probability that Senior becomes a grandparent depends on the shape of her or his preferences that are common to Junior (i.e., $u, v$, and $v$ ).

\footnotetext{
${ }^{7}$ At an interior optimum, if $\bar{h}$ is sufficiently large so that one does not desire to spend additional time with children while such additional time is not needed to rear them, then both $h_{1}^{\prime}$ and $l_{1}^{\prime}$ increase, and $x^{\prime}$ declines (less than $x$ increases), with the time transfer $x$ from Senior to Junior, because the latter relaxes Junior's time constraint. The same is true, via a relaxation of the budget constraint, for the asset transfer $t$. Therefore, the latter, too, increases the probability of becoming a grandparent.
} 
Next, we analyze the intergenerational transfer and labor supply choices of Senior. We focus on an interior solution for labor supply, leisure, and monetary transfers, for both a Senior with a grandchild and one without. That is, $\left(h_{1}, l_{1}, t_{1}\right)>(0,0,0)$ and $\left(h_{0}, l_{0}, t_{0}\right)>(0,0,0)$. Denoting by $\lambda$ the multiplier on Senior's budget constraint, and given that, at the optimum, $u_{c}=\lambda$, the optimum for a Senior with a grandchild $(g=1)$ is characterized, in addition to the time and budget constraints, by the following conditions:

$$
\begin{aligned}
t_{1} & : \quad u_{c}\left(w h_{1}-t_{1}\right)=\rho u_{c}\left(w^{\prime} h_{1}^{\prime}-\left(\bar{h}-x^{\prime}-x\right) p+t_{1}\right) \\
x & : v_{l}\left(1-h_{1}-x\right) \geq v_{x}(x)+\rho u_{c}\left(w^{\prime} h_{1}^{\prime}-\left(\bar{h}-x^{\prime}-x\right) p+t_{1}\right) p, \\
h_{1} & : \quad v_{l}\left(1-h_{1}-x\right)=w u_{c}\left(c_{1}\right) .
\end{aligned}
$$

The corresponding conditions for a Senior without a grandchild $(g=0)$ are,

$$
\begin{aligned}
t_{0} & : u_{c}\left(w h_{0}-t_{0}\right)=\rho u_{c}\left(w^{\prime} h_{0}^{\prime}+t_{0}\right) \\
x & : v_{l}\left(1-h_{0}\right) \leq v_{x}(0)+\rho u_{c}\left(w^{\prime} h_{1}^{\prime}-\left(\bar{h}-x^{\prime}\right) p+t_{1}\right) p, \\
h_{0} & : \quad v_{l}\left(1-h_{0}\right)=w u_{c}\left(c_{0}\right) .
\end{aligned}
$$

If condition (7) holds as a strict inequality at $x=0$, then a grandparent transfers no time: the value to Senior of the marginal unit of time in terms of either additional leisure or additional consumption (via additional work) exceeds the value of spending that unit of time with Baby, net of the benefit for Junior in terms of a relaxation of Junior's budget constraint. In this case Senior sets $x=0$. This corresponds to the case in which (10) holds as an equality. In other words, a Senior who does not sufficiently care for Baby and Junior behaves, in terms of intergenerational time transfers, exactly like a Senior without a grandchild.

However, when (10) holds as a strict inequality, then a Senior without Baby in the family is constrained into a suboptimal allocation of time. This Senior would like to spend time with the grandchild but cannot because Junior has not produced a Baby. When Baby appears, a reallocation of Senior's time takes place according to conditions (7) and (Eq. 8). If we keep the transfer $t$ constant, then (because $h_{0}$ and $l_{0}$ are at an interior) such reallocation necessarily takes the form of reduced leisure and reduced labor supply for a Senior who becomes a grandparent. However, the monetary transfer, too, is adjusted when Baby appears, according to condition (6). If $v_{x}$ is sufficiently large and $\rho$ is sufficiently small then both $l$ and $h$ decrease. However, if $v_{x}$ is sufficiently small and $\rho$ is sufficiently large then $l$ decreases and $h$ increases. In other words, if Senior cares sufficiently about Junior's welfare but not as much about spending time with Baby, then he or she may transfer more in terms of consumption (a higher $t$ ) and transfer little time or no time at all. In this case leisure would still decrease, but labor supply would increase. Therefore, the labor supply response of becoming a grandparent is ambiguous from a theoretical viewpoint. The remainder of the paper aims at resolving this question empirically.

To connect the model with the empirical analysis, notice that the treatment effect of interest for a Senior who is always at an interior (intensive margin effect, conditional on $h_{1}>0$ and $h_{0}>0$ ) is

$$
h_{1}-h_{0}=v_{l}^{-1}\left(w u_{c}\left(c_{0}\right)\right)-v_{l}^{-1}\left(w u_{c}\left(c_{1}\right)\right)-x,
$$

where $v_{l}^{-1}$ is the inverse of $v_{l}$. The effect for a Senior who may be or end up at a corner (extensive margin effect) can be expressed as a probability function, assuming the econometrician does not observe preferences $\left(u_{c}\right.$, or $v_{l}$, or neither of the two):

$$
\operatorname{Pr}\left(h_{1}>0\right)-\operatorname{Pr}\left(h_{0}>0\right)=\operatorname{Pr}\left(v_{l}(1-x) \leq w u_{c}\left(c_{1}\right)\right)-\operatorname{Pr}\left(v_{l}(1) \leq w u_{c}\left(c_{0}\right)\right),
$$


and the overall labor supply effect is the product of the two.

\section{Empirical analysis}

\subsection{Data}

We use data on household heads and their spouses from all of the available waves, to date, of the PSID (1968-2011). ${ }^{8}$ This longitudinal data set is especially suited for the research question we address in this paper. Its key feature in this respect, besides a unique time span for survey data, is an endogenous intergenerational structure: when a child born to (or adopted by) a sample member after the initial interview leaves a sample household to form her or his own household, the latter is added to the sample. In the PSID, these endogenous additions are referred to as "split-offs". This mechanism implies that all descendants of the original, core sample families are observed for many years if they were not yet born or if they were still living with their parents at the time of the first interview. Therefore, grandparents and parents of sufficiently young cohorts can be linked to their grandchildren and children, regardless of whether they live in the same household or not. Such linkage is possible thanks to the Family Identification Mapping System (FIMS), a supplementary data set specifically created for intergenerational analyses. ${ }^{9}$ Because we observe the entire life cycle (or long portions of it) for several thousand individuals, we can observe the same individuals both when they become parents and when, many years later, they become grandparents.

We restrict the sample to PSID core sample individuals born no earlier than 1927. That is, individuals who were at most 40 years old at the time of the first interview in 1967 or later years. This criterion ensures that at least some of the children (Junior) of these individuals (Senior) are still present in the household at the time of the first interview and eventually become part of the survey as split-offs, so that grandchildren (Baby), if any, are observed when they appear. After applying this selection criterion we are left with an unbalanced panel of about 28,000 individuals (56\% of whom have a non-zero sampling weight), each observed on average for 11.4 waves (min 1 year, max 37 waves). ${ }^{10}$

Table 1 reports summary statistics for the four decades spanned by the data, computed applying individual sampling weights. The differences across decades reflect both general demographic and social changes (this is the case for age, ethnicity, marital status, education, fertility etc.) and the endogenous demographic structure of the sample. ${ }^{11}$ For instance, we see in this table that the fraction of individuals who are grandparents ("Grandparent") increases over time, while the fraction of those who become grandparents at some point during the life cycle ("Ever grandparent") decreases over time. This is due to the fact that the oldest cohort in the sample was 40 years old in 1967. As this and younger cohorts become older we see the fraction of grandparents increasing.

\footnotetext{
${ }^{8}$ The 2011 wave was released during the Summer of 2013.

${ }^{9}$ Notice that attrition does not distort such mapping: it's enough that the household of one's descendant is observed for just one year.

${ }^{10}$ When interpreting this average one must keep in mind that the PSID was at an annual frequency until the 1997 wave, and biennial thereafter.

${ }^{11}$ The reason why the importance of the White non-Hispanic and Black non-Hispanic populations is at odds with the national shares even after applying sampling weights is that the evolution of the PSID core sample is a pure demographic evolution of the 1967 American population that does not take into account immigration. See Fiorito and Zanella (2012) for an illustration of this point.
} 
On the other hand, because new, young cohorts enter the sample and are not observed as old individuals, the fraction of sample individuals who are ever observed as grandparents declines over time. The fact that these two series converge is a natural consequence of another fact; namely that by restricting to the more recent decades one observes mostly young cohorts with short histories in the panel. This same line of reasoning applies to the fraction of individuals who are parents ("Parent") and the fraction of those who become parents at some point during the life cycle ("Ever parent"), which exhibit the same pattern.

Table 1: Summary statistics, full sample, by cohort

\begin{tabular}{lcccc}
\hline & $1967-1979$ & $1980-1989$ & $1990-1999$ & $2000-2010$ \\
\cline { 2 - 5 } Age & 32.1 & 37.1 & 41.6 & 46.6 \\
Birth year & 1941.7 & 1947.7 & 1952.2 & 1958.7 \\
Male & 0.455 & 0.456 & 0.461 & 0.466 \\
White non-Hispanic & 0.845 & 0.830 & 0.816 & 0.813 \\
Black non-Hispanic & 0.102 & 0.116 & 0.123 & 0.131 \\
Married & 0.808 & 0.724 & 0.688 & 0.641 \\
Widowed & 0.013 & 0.022 & 0.034 & 0.051 \\
Divorced & 0.067 & 0.105 & 0.116 & 0.130 \\
Separated & 0.031 & 0.031 & 0.028 & 0.025 \\
Less than High School & 0.250 & 0.170 & 0.135 & 0.097 \\
High School & 0.421 & 0.407 & 0.388 & 0.360 \\
College & 0.177 & 0.225 & 0.250 & 0.288 \\
Parent & 0.706 & 0.768 & 0.780 & 0.780 \\
Ever parent & 0.832 & 0.871 & 0.848 & 0.794 \\
Children in household & 1.59 & 1.02 & 0.83 & 0.65 \\
Total fertility & 2.36 & 2.33 & 2.18 & 1.94 \\
Grandparent & 0.068 & 0.180 & 0.248 & 0.308 \\
Ever grandparent & 0.617 & 0.517 & 0.433 & 0.346 \\
Employed & 0.788 & 0.832 & 0.773 & 0.734 \\
Self-employed & 0.080 & 0.102 & 0.107 & 0.108 \\
Disability & 0.085 & 0.133 & 0.158 & 0.176 \\
Earnings & 32.2 & 34.8 & 38.9 & 37.5 \\
Family income & 70.7 & 76.9 & 77.7 & 79.1 \\
Individuals & 7,584 & 8,219 & 9,665 & 9,184 \\
Observations & 62,078 & 64,428 & 56,381 & 42,929 \\
\hline \hline
\end{tabular}

Notes: Sample means for household heads and their spouses, PSID core sample 1967-2010, born in 1927 or later. Earnings and total family income are expressed in thousands of constant 2010 dollars. Individual sampling weights are applied, and the weighted sample is an unbalanced panel of about 15,000 distinct individuals.

In our analysis we use only individuals in this sample who satisfy the following three criteria: (1) are biological or adoptive parents; (2) their oldest child is at least 14 years old; (3) are at most 70 years old. The first two criteria ensure that individuals in the final sample are comparable: only those who satisfy them may be or become grandparents. The third criterion, coupled with the sec- 
ond, restricts the sample to working age grandparents and potential grandparents. Criteria (1)-(3) reduce the sample to about 11,000 individuals (2/3 of whom have a non-zero sampling weight). Table 2 reports the previous and additional summary statistics in the two groups which are the primary focus of this paper: those who satisfy criteria (1)-(3) and become grandparents at some point between 1967 and 2010, and those who satisfy criteria (1)-(3) but do not become grandparents as of 2010. This table is constructed pooling all observations across years and applying individual sampling weights. Table 3 reports the corresponding gender breakdown.

In order to ensure the comparability of the two groups in the light of the differences emerging from Table 1, we restrict in Table 2 and Table 3 to individuals born between 1927 and 1940 and who are between 40 and 70 years old at any point between 1967 and 2010. Table 2 shows that parents who eventually become grandparents are different from those who don't along most of the dimensions considered. The exceptions are exogenous characteristics such as gender, being widowed, and having a condition that limits the amount or type of work one can do ("Disability"). In particular, those who become grandparents are younger (because they became parents almost 3 years earlier, on average), are more likely to be married whites, have higher fertility, are more likely to be employed, and have higher income.

Education seems balanced in Table 2, but Table 3 reveals an asymmetry between men and women. Among men, it is the more educated who become grandparents. Among women, the opposite holds. These and other differences emerging from Table 3 should be interpreted keeping in mind the different incidence of singe mothers vs. single fathers, as well as the different mortality rates of men and women late in the life cycle. We also see in these tables that the average number of grandchildren is about 5.7. The median (not reported in the table) is 5. According to our data, the average age Americans born between 1927 and 1940 became grandparents in the 1967-2010 period was 48.9, with a gender difference of 3 years: 50.5 for men and 47.6 for women, in line with estimates from other sources as well as national trends in women's age at first birth. ${ }^{12}$ The median was 50 for men and 47 for women. Most of these differences between parents who become grandparents and those who don't persist in a regression of the "Ever grandparent" dummy on the demographic and socioeconomic characteristics reported in these tables, age dummies and year dummies. ${ }^{13}$. We will discuss the consequence of such obvious non-randomness of the grandparent status after presenting OLS estimates.

\subsection{OLS and fixed-effects analysis}

We organize our empirical analysis around the following baseline linear model, in line with the theory (i.e., Eq. 12 and Eq. 13):

$$
L_{i t}=\alpha+\beta g_{i t}+\lambda \mathbf{a}+\eta \tau+\varepsilon_{i t},
$$

where $L_{i t}$ is a labor supply measure for individual $i$ in year $t, \alpha$ is a constant, $g_{i t}$ is a dummy variable equal to 1 if individual $i$ is a grandparent at time $t$, and 0 otherwise (i.e., this variable is equal to 0 at the baseline and switches permanently to 1 when the individual becomes a grandparent), $\mathbf{a}$ and $\tau$ are

\footnotetext{
12 According to the OECD Family Database, the average age of American women at the birth of their first child was about 25 in 2006, up from about 22.5 in 1970.

13 The regression output is available from the authors upon request
} 
Table 2: Summary statistics, Seniors by grandparenting status

\begin{tabular}{lcccc}
\hline & $\begin{array}{c}\text { Become } \\
\text { grandparents }\end{array}$ & $\begin{array}{c}\text { Do not become } \\
\text { grandparents }\end{array}$ & Difference & p-value \\
\cline { 2 - 5 } Age & 54.0 & 54.9 & -0.9 & 0.00 \\
Birth year & 1932.7 & 1932.5 & 0.2 & 0.00 \\
Male & 0.434 & 0.429 & 0.005 & 0.64 \\
White non-Hispanic & 0.850 & 0.770 & 0.080 & 0.00 \\
Black non-Hispanic & 0.092 & 0.165 & -0.073 & 0.00 \\
Married & 0.812 & 0.757 & 0.055 & 0.00 \\
Widowed & 0.082 & 0.082 & 0.030 & 0.95 \\
Divorced & 0.083 & 0.144 & -0.061 & 0.00 \\
Separated & 0.018 & 0.010 & 0.008 & 0.00 \\
Less than High School & 0.265 & 0.240 & 0.025 & 0.00 \\
High School & 0.416 & 0.422 & -0.005 & 0.59 \\
College & 0.173 & 0.174 & -0.001 & 0.90 \\
Age became parent & 23.5 & 26.2 & -2.7 & 0.00 \\
Years since parent & 30.5 & 28.7 & 1.8 & 0.00 \\
Children in household & 0.51 & 0.31 & 0.20 & 0.00 \\
Total fertility & 3.54 & 2.00 & 1.54 & 0.00 \\
Grandparent & 0.689 & 0 & - & - \\
Ever grandparent & 1 & 0 & - & - \\
Age became grandparent & 48.9 & - & - & - \\
Years since grandparent & 10.0 & - & - & - \\
Number of grandchildren & 2.93 & - & - & - \\
Total number of grandchildren & 5.66 & - & - & - \\
Employed & 0.651 & 0.615 & 0.036 & 0.00 \\
Self-employed & 0.120 & 0.091 & 0.029 & 0.00 \\
Disability & 0.227 & 0.230 & -0.003 & 0.73 \\
Earnings & 31.4 & 28.0 & 3.39 & 0.00 \\
Family income & 89.1 & 80.2 & 8.9 & 0.00 \\
Individuals & 1,682 & 200 & & - \\
Observations & 35,540 & 3,291 & & - \\
\hline \hline
\end{tabular}

Notes: Sample means for household heads and their spouses, PSID core sample 1967-2010, born between 1927 and 1940, who are no younger than 40 and no older than 70, and who have at least one biological or adoptive child who is 14 or older. Individuals in the first column become grandparents at some point between 1967 and 2010; individuals in the second column do not become grandparents as of 2010. The p-value refers to a t-test of the null hypothesis that the difference is zero. Earnings and total family income are expressed in thousands of constant 2010 dollars. Individual sampling weights are applied. 
Table 3: Summary statistics, Seniors by grandparenting status and gender

\begin{tabular}{lcccc}
\hline & \multicolumn{2}{c}{ Men } & \multicolumn{2}{c}{ Women } \\
& $\begin{array}{c}\text { Become } \\
\text { grandparents }\end{array}$ & $\begin{array}{c}\text { Do not become } \\
\text { grandparents }\end{array}$ & $\begin{array}{c}\text { Become } \\
\text { grandparents }\end{array}$ & $\begin{array}{c}\text { Do not become } \\
\text { grandparents }\end{array}$ \\
\cline { 2 - 5 } Age & 54.2 & 55.2 & 53.9 & 54.7 \\
Birth year & 1932.6 & 1932.2 & 1932.8 & 1932.7 \\
White & 0.885 & 0.768 & 0.823 & 0.773 \\
Black & 0.069 & 0.173 & 0.109 & 0.159 \\
Married & 0.891 & 0.861 & 0.752 & 0.679 \\
Widowed & 0.035 & 0.044 & 0.119 & 0.111 \\
Divorced & 0.062 & 0.063 & 0.100 & 0.205 \\
Separated & 0.010 & 0.012 & 0.023 & 0.009 \\
Less than High School & 0.261 & 0.304 & 0.268 & 0.193 \\
High School & 0.344 & 0.282 & 0.471 & 0.527 \\
College & 0.238 & 0.221 & 0.123 & 0.139 \\
Age became parent & 25.0 & 28.2 & 22.3 & 24.6 \\
Years since parent & 29.2 & 27.0 & 31.6 & 30.0 \\
Children in household & 0.57 & 0.42 & 0.47 & 0.23 \\
Total fertility & 3.42 & 2.09 & 3.63 & 1.94 \\
Grandparent & 0.638 & 0 & 0.729 & - \\
Ever grandparent & 1 & 0 & 1 & - \\
Age became grandparent & 50.5 & - & 47.6 & - \\
Years since grandparent & 9.2 & - & 10.6 & - \\
Number of grandchildren & 2.57 & - & 3.20 & - \\
Total number of grandchildren & 5.52 & - & 5.78 & - \\
Employed & 0.767 & 0.759 & 0.562 & 0.507 \\
Self-employed & 0.190 & 0.125 & 0.060 & 0.064 \\
Disability & 0.216 & 0.249 & 0.236 & 0.215 \\
Earnings & 53.1 & 45.4 & 14.8 & 15.0 \\
Family income & 99.1 & 91.2 & 81.3 & 71.9 \\
Individuals & 669 & 92 & 1,013 & 108 \\
Observations & 13,886 & 1,385 & 21,654 & 1,906 \\
\hline \hline
\end{tabular}

Notes: Sample means for household heads and their spouses, by gender, PSID core sample 1967-2010, born between 1927 and 1940, who are no younger than 40 and no older than 70, and who have at least one biological or adoptive child who is 14 or older. Individuals in the first column become grandparents at some point between 1967 and 2010; individuals in the second column do not become grandparents as of 2010. The p-value refers to a t-test of the null hypothesis that the difference is zero. Earnings and total family income are expressed in thousands of constant 2010 dollars. Individual sampling weights are applied. 
vectors of age and year dummies, and $\lambda$ and $\eta$ are the associated vectors of coefficients. ${ }^{14}$ Notice that because of the way $g_{i t}$ is defined (and because of the longitudinal nature of the data), this empirical model exploits two different margins of variation: the event of becoming a grandparent earlier than other individuals (cross-sectional margin), and the timing of such an event over the life cycle (longitudinal margin).

We use three different measures of labor supply, $L_{i t}$. First, hours conditional on being employed (i.e., excluding individuals reporting zero hours), denoted $h_{i t}$. In this case $\beta$ is the intensive margin effect conditional on being at an interior:

$$
\beta=\mathbb{E}\left(h_{i t} \mid g_{i t}=1, h_{i t}>0\right)-\mathbb{E}\left(h_{i t} \mid g_{i t}=0, h_{i t}>0\right),
$$

which corresponds to $h_{1}-h_{0}$ in the model, Eq. 12. Second the employment indicator (i.e., a dummy taking value 1 if an individual reports a strictly positive number of hours in a given year, and 0 otherwise), denoted $e_{i t}$. In this case $\beta$ is the extensive margin effect:

$$
\beta=\mathbb{E}\left(\mathbb{I}\left[h_{i t}>0\right] \mid g_{i t}=1\right)-\mathbb{E}\left(\mathbb{I}\left[h_{i t}>0\right] \mid g_{i t}=0\right),
$$

which corresponds to $\operatorname{Pr}\left(h_{1}>0\right)-\operatorname{Pr}\left(h_{0}>0\right)$ in the model, Eq. 13. Finally, unconditional hours (i.e., including individuals with zero hours), denoted $H_{i t}$. In this case $\beta$ is a conflation of intensive and extensive margin effects:

$$
\begin{aligned}
\beta= & \mathbb{E}\left(h_{i t} \mid g_{i t}=1\right)-\mathbb{E}\left(h_{i t} \mid g_{i t}=0\right) \\
= & \mathbb{E}\left(h_{i t} \mid g_{i t}=1, h_{i t}>0\right) \mathbb{E}\left(\mathbb{I}\left[h_{i t}>0\right] \mid g_{i t}=1\right) \\
& -\mathbb{E}\left(h_{i t} \mid g_{i t}=0, h_{i t}>0\right) \mathbb{E}\left(\mathbb{I}\left[h_{i t}>0\right] \mid g_{i t}=0\right),
\end{aligned}
$$

which corresponds to $h_{1} \operatorname{Pr}\left(h_{1}>0\right)-h_{0} \operatorname{Pr}\left(h_{0}>0\right)$ after combining Eq. 12 and Eq. 13 .

Henceforth, we restrict the analysis to parents born in 1927 or later, who are no older than 70 and whose older child is at least 14. That is, using the terminology introduced in Section 2, we focus on Senior's labor supply. In this group, 39\% of all pooled observations correspond to grandparents $(68 \%$ if restricting to the group 50 or older, $24 \%$ if restricting to the group below 50). Among these, $95 \%$ have at least one grandchild who is 12 years old or younger. Furthermore, here and in all of the following regressions, standard errors are robust to heteroskedasticity and are clustered at the individual level. Contrary to what we did in Section 3.1 to obtain representative means, we do not apply sampling weights to this and all following regressions. This choice follows Solon, Haider, and Wooldridge (2013), who suggest that in a regression context it may be preferable to just condition on variables, if available, that account for the unequal sampling probabilities relative to the population of interest. Because the imbalance of the PSID core sample relative to the American population is chiefly due to differences in income at the time the sample was constructed in $1967,{ }^{15}$ conditioning on family income in that year (denoted $y 67$ ) is a parsimonious way of retaining a large sample size (weighting would cause the loss of about $1 / 3$ of the sample because

\footnotetext{
${ }^{14}$ We refrain from including in the regression additional controls (such as education, marital status, etc.) that would only exacerbate the endogeneity problem discussed below. However, we will later report the results from an extended specification with several additional regressors.

15 The "core sample" of the PSID was constructed by merging two subsamples: the SRC subsample, which was extracted from the Census and was representative of the US population at the time, and the SEO subsample, which was a sample of low-income households.
} 
these observations are assigned a zero weight) while taking into account the different sampling probabilities.

OLS estimates of Eq. 14 are reported in Table 4. This table shows a modest (about 55 hours per year) negative intensive margin effect for employed men, no intensive margin effect for employed women, and a significant extensive margin effect for both men and women of 3.7 and 5.4 percentage points, respectively. The overall labor supply effect is negative and significant: about 125 hours per year for men, and about 90 for women.

The obvious problem with these estimates is that becoming a grandparent, even conditional on being a Senior whose youngest Junior is at least 14 years old and despite being determined by someone else's (one's Junior) fertility choices, is not an exogenous event. Table 2 is a testament to this fact. As the model in section 2 illustrates, there are at least two sources of endogeneity in an equation like Eq. 14: unobserved heterogeneity and simultaneity. The first implies the possibility that one's unobserved taste for work correlates with the probability of becoming a grandparent. For instance, preferences for fertility may be transmitted from Senior to Junior-like in the model. In this case, because fertility and labor supply are jointly determined, after Junior reaches fertility age Senior's unobserved taste for work correlates with the grandparent status. Also, Seniors who have a strong desire to become grandparents for reasons related to their preference for leisure (e.g., a comparative disadvantage in market production relative to home production) may exert pressure on Junior to induce them to produce Baby.

Table 4: OLS estimates

\begin{tabular}{lcccccc}
\hline & $(1)$ & $(2)$ & $(3)$ & $(4)$ & $(5)$ & $(6)$ \\
\cline { 2 - 7 }$g_{i t}$ & $h_{i t}$ & $h_{i t}$ & $e_{i t}$ & $e_{i t}$ & $H_{i t}$ & $H_{i t}$ \\
& men & women & men & women & men & women \\
\cline { 2 - 7 }$y 67_{i}$ & -53.6 & 6.4 & -0.037 & -0.054 & -124.3 & -87.2 \\
& $(17.2)$ & $(13.8)$ & $(0.009)$ & $(0.009)$ & $(24.4)$ & $(18.8)$ \\
Constant & 1.6 & -0.2 & 0.001 & 0.001 & 2.8 & 1.2 \\
& $(0.2)$ & $(0.2)$ & $(0.000)$ & $(0.000)$ & $(0.4)$ & $(0.3)$ \\
& 2115.5 & 1743.5 & 0.872 & 0.726 & 1851.0 & 1263.5 \\
Observations & 37,722 & 48,331 & 44,998 & 71,965 & 44,998 & 71,965 \\
Fixed effects & No & No & No & No & No & No \\
Age dummies & Yes & Yes & Yes & Yes & Yes & Yes \\
Year dummies & Yes & Yes & Yes & Yes & Yes & Yes \\
\hline \hline
\end{tabular}

Notes: OLS estimates from Eq. 14, PSID core sample, waves 1968-2011, individuals (Seniors, in Section 2) no older than 70 who have at least one child (Junior, in Section 2) who is 14 or older. The dependent variables are, alternately, annual hours of work for pay conditional on being employed (i.e., excluding zero hours, $h_{i t}$ ), an employment dummy $\left(e_{i t}\right)$, and unconditional annual hours of work for pay (i.e., including zero hours, $\left.H_{i t}\right)$. Independent variable $g_{i t}$ is a dummy assuming value 1 if individual $i$ has at least one grandchild (Baby) at time $t$, and zero otherwise. Covariate $y 67_{i}$ is family income in 1967 and controls for unequal sampling probabilities in a regression framework (Solon et al. (2013)). Robust standard errors in parentheses, clustered at the individual level.

This form of endogeneity can be mitigated by individual fixed effects, which is feasible be- 
cause we have a panel. In this case, family income in 1967 is constant for an individual and so is subsumed in the fixed effect. Results are reported in Table 5. This table confirms a modest negative intensive margin effect on employed men of about 50 hours, and shows a positive effect of similar magnitude on employed women's hours. The extensive margin effects becomes smaller and insignificant relative to the OLS estimates. Overall labor supply, according to these fixed-effects estimates, declines by almost 80 hours per year for grandfathers and increases by almost 50 hours per year for grandmothers.

Notice that all of the fixed-effects coefficients on $g_{i t}$ are above the OLS estimates. This suggests the presence of unobserved components of preferences that positively affect labor supply, negatively correlate with the grandparent status, and so bias the OLS estimates downward. The omitted variable bias formula indicates that this happens, for instance, if Senior has an unobserved taste for both reduced labor supply and higher fertility which is also transmitted to Junior. In this case, those who are more likely to become grandparents are also those who are more likely to work less. Fixed effects account for this correlation and produce larger coefficients.

Table 5: Fixed-effects estimates

\begin{tabular}{lcccccc}
\hline & $(1)$ & $(2)$ & $(3)$ & $(4)$ & $(5)$ & $(6)$ \\
\cline { 2 - 7 } & $h_{i t}$ & $h_{i t}$ & $e_{i t}$ & $e_{i t}$ & $H_{i t}$ & $H_{i t}$ \\
men & women & men & women & men & women \\
\cline { 2 - 7 }$g_{i t}$ & -46.4 & 50.5 & -0.013 & 0.011 & -76.2 & 47.3 \\
Constant & $(14.8)$ & $(13.2)$ & $(0.008)$ & $(0.007)$ & $(20.1)$ & $(14.5)$ \\
& 2203.3 & 1697.2 & 0.889 & 0.678 & 1956.0 & 1127.3 \\
& $(26.8)$ & $(23.1)$ & $(0.013)$ & $(0.012)$ & $(35.1)$ & $(22.9)$ \\
Individuals & 4,144 & 5,808 & 4,318 & 6,418 & 4,318 & 6,418 \\
Observations & 37,722 & 48,331 & 44,998 & 71,965 & 44,998 & 71,997 \\
Fixed effects & Yes & Yes & Yes & Yes & Yes & Yes \\
Age dummies & Yes & Yes & Yes & Yes & Yes & Yes \\
Year dummies & Yes & Yes & Yes & Yes & Yes & Yes \\
\hline \hline
\end{tabular}

Notes: Fixed Effects-OLS estimates from Eq. 14, PSID core sample, waves 1968-2011, individuals (Seniors, in Section 2) no older than 70 who have at least one child (Junior, in Section 2) who is 14 or older. The dependent variables are, alternately, annual hours of work for pay conditional on being employed (i.e., excluding zero hours, $h_{i t}$ ), an employment dummy $\left(e_{i t}\right)$, and unconditional annual hours of work for pay (i.e., including zero hours, $\left.H_{i t}\right)$.. Independent variable $g_{i t}$ is a dummy assuming value 1 if individual $i$ has at least one grandchild (Baby) at time $t$, and zero otherwise. Robust standard errors in parentheses, clustered at the individual level.

\subsection{Instrumental variable analysis}

The second form of endogeneity stems from possible strategic interactions. Even our extremely simple model makes clear that the probability of becoming a grandparent increases in the expected time transfer from the old to the young, because the latter reduces the cost of child bearingEq. 5 can be though of as a "stochastic incentive compatibility constraint". In this case, causation 
runs the other way: it is (Junior's expectations over) Senior's labor supply that causes Senior to become a grandparent. For instance, if one's grown-up children anticipate that one is going to retire next year and so will be available (and willing) to help with child care, this makes one more likely to become a grandparent the year he or she reduces labor supply, or shortly after. The ensuing simultaneity is a trickier form of endogeneity which cannot be mitigated by fixed effects. A solution is an exclusion restriction in the form of an instrument for the probability of becoming a grandparent, unrelated to life cycle labor supply.

\subsubsection{Finding instruments}

A way of constructing such an instrument is to draw from the literature on fertility and labor supply we have briefly summarized in Section 1. In Angrist and Evans (1998) the natural experiment is the variation in sibling sex composition across couples. They exploit the long-standing observation that couples whose first two children are either two boys or two girls have a stronger tendency to have at least one additional child, because of a taste for variety. Because the higher the number of children one has the higher the probability that one will become a grandparent, this is also a valid instrument for $g_{i t}$ in Eq. 14. We report in Figure 2 the fraction of individuals in the PSID born between 1927 and 1940 who become grandparents as of 2010, as a function of their total, lifetime fertility. Individuals with only one child have an unconditional probability of about 58\% of becoming grandparents at some point during their life. ${ }^{16}$ This probability increases to about $87 \%$ for those with two children, to more than $92 \%$ for those with three children, and so on, until it becomes virtually $100 \%$ for those with more than 5 children.

Figure 2: Total own fertility and probability of becoming grandparent

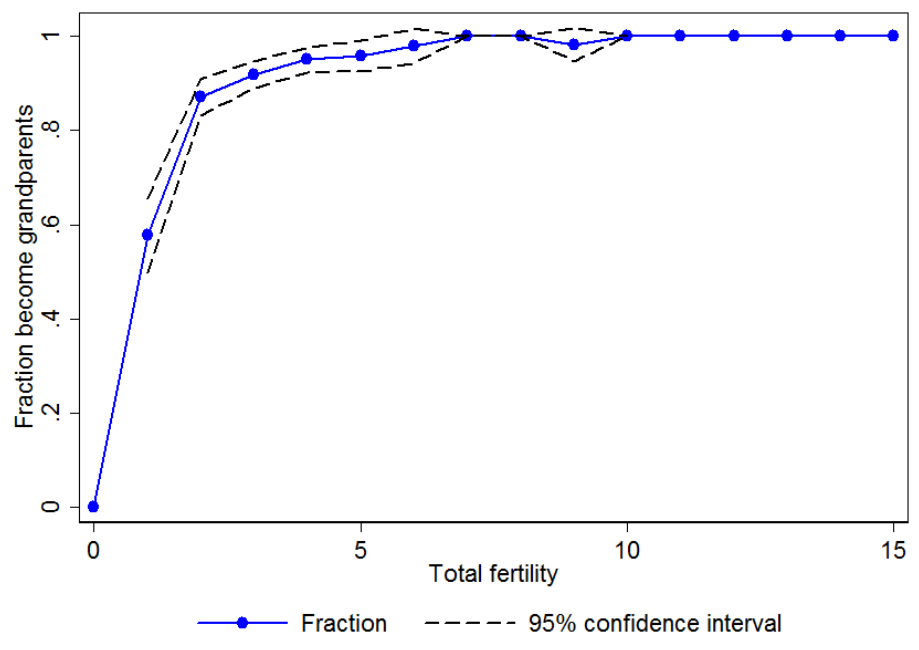

Notes: The figure shows the fraction of individuals in our PSID sample who are born between 1927 and 1940 and who become grandparents before 2010 as a function of their total, lifetime fertility. Individual sampling weights are applied.

\footnotetext{
16 This probability is underestimated because the younger cohorts in this group are not observed through their old years, which lie ahead of 2010
} 
Sibling sex composition, however, affects the probability of becoming a grandparent via an additional channel, namely timing. Because girls mate and have children before boys, an individual whose first two children are two girls and who eventually becomes a grandparent will have grandchildren, ceteris paribus, earlier than her or his counterpart whose first two children are of any other gender mix. We show below that, in fact, the timing channel appears to be more important than the fertility channel. Formally, this instrument is defined as follows:

$$
\text { twogirls }=\left\{\begin{array}{l}
1 \text { if first two children are females, } \\
0 \text { if first two children are of another mix. }
\end{array}\right.
$$

One drawback of this instrument is that it is not defined for those Seniors who had just one child, and so removes them from the sample. This means a reduced sample size. But there is a second, more worrisome consequence. It has been observed (see, e.g., Lundberg (2005) and, more recently, Ichino, Lindstrom, and Viviano (2013)) that although the gender of one's first child is overwhelmingly random in the U.S. and other places where selective abortion is not an issue, precisely because of possible preferences for the gender mix of one's offspring the gender and number of subsequent children may well be endogenous. This, in turn, means two things. First, restricting the sample to individuals with at least two children may lead one to focus on a group that is systematically different from the rest. Second, possible violation of the instrument exclusion restriction.

In order to overcome these limitations we also employ the gender of one's first child as an alternative instrument. The rationale is, again, twofold. First, Dahl and Moretti (2008) show that American couples with a first-born girl tend to have more children, a "demand for sons" that was previously thought to be still present in some less developed countries but absent from most developed ones. Therefore, this variable, too, may affect the probability of becoming a grandparent in the PSID. One additional advantage is that as far as the fertility channel is exploited, this is a stronger instrument because, as Figure 2 illustrates, the effect of own fertility on the probability of becoming a grandparent is much stronger when moving from one to two children than when moving from two to three. Second, as before, girls begin reproducing earlier than boys. Formally, this alternative instrument is defined as follows:

$$
\text { girlfirst }=\left\{\begin{array}{l}
1 \text { if first child is female, } \\
0 \text { if first child is male }
\end{array}\right.
$$

While the gender of one's first child is arguably as good as randomly assigned in the U.S., possible violation of the exclusion restriction is an issue because of well-established evidence that a first-born girl affects parents' behavior in ways that may be reflected in the allocation of time at different points of the life cycle. Lundberg (2005) offers a comprehensive survey of such evidence, and both Dahl and Moretti (2008) themselves and Ichino et al. (2013)) have more recently produced additional data about the consequences of a first-born girl vs. a first-born boy.

We defer a discussion of the consequences of this threat to our identification strategy until after the presentation of our baseline results. As it turns out, when the violation of the exclusion restriction is produced by the main effects documented in the literature then we can establish the sign of the bias. This, if any, is such that we can still interpret the estimates obtained with the girlfirst instrument as lower bounds, in absolute value. 
Table 6 shows the effect of the sibling-sex mix and of the gender of one's first child on own fertility, grandparent status, and age one becomes a grandparent, by gender. The fraction of the sample who had a certain sibling-sex mix at first two births and a certain gender at first birth are virtually identical to those reported by Angrist and Evans (1998), Table 3, using Census data. Most notably, Table 6 suggests that in our sample the timing channel is more important than the fertility channel: while in this table we don't see significant fertility differences across the two groups defined by twogirls and girlfirst (although the differences are systematically positive) we do see large differences in the timing of becoming a grandparent across the two groups defined by the instruments. Women who had two girls as first two children become grandmothers more than 2 years earlier than those who had a different mix. And both men and women whose first child was a girl become grandparents earlier than those who had a boy. The difference is about 1 and 2 years, respectively. Table 7 reproduces these differences in a regression framework (except for the effect of $t$ wogirls and girl first on the probability of ever becoming a grandparent, which is related to our first stage and which we discuss separately), conditioning on age and year dummies. This table confirms, by and large, the unconditional effects reported in Table 6. In sum, both instruments chiefly operate through the timing channel, and there seem to be advantages in using both of them as an alternative to each other. Eventually, girlfirst will be our preferred instrument because, as one would expect, it performs much better than twogirls.

Notice that both when using the sibling sex mix and the gender of first child, the instrument is a constant throughout the life cycle, and so we cannot, at the same time, employ the within estimator. Therefore, our IV estimates are based on pooled two-stage least squares.

\subsubsection{Baseline IV estimates}

Table 8 reports first-stage estimates for each of the two instruments, by gender. This table shows that having had two girls as the first two children increases the probability of being a grandparent at any point in time, after controlling for age and time effects, by about 6 percentage points for men and 8 percentage points for women. The effect of having had a girl as first child in the larger sample of those with at least one child is essentially the same. The F-statistic on the excluded instrument indicates that this second instrument is, as expected, stronger. In addition to a larger sample size, this is because the shock to the probability of becoming a grandparent when moving from 1 to 2 children is stronger than the corresponding shock when moving from 2 to 3 , as illustrated in Figure 2. Table 8 also shows that both instruments are stronger for women than for men. Given that we don't see major gender differences in the relevant portion of Table 6 , this is mostly due to the larger female sample size. ${ }^{17}$ In turn, the larger female component of the sample is due both to the different mortality rate of men and women late in the life cycle and to the unequal sampling probabilities - when applying sampling weights, as Table 1 shows, the gender ratio is much more balanced.

Second-stage results are reported in Table 9 and Table 10 for the twogirls and girlfirst instruments, respectively. Table 9 shows a consistently negative effect of becoming a grandparent on Senior's labor supply, except for men's extensive margin. This effect, however, is never precisely estimated: instrument $t$ wogirls does not help detecting statistically significant effects. Ta-

\footnotetext{
${ }^{17}$ This is confirmed by the following experiment: we randomly dropped observations in the female sample so to reduce its size to the male sample, and we estimated the first-stage equations on the resulting data. The F-stat on the excluded instruments drops to little above the level obtained in the male sample.
} 
Table 6: Fertility and grandparent status by gender of first child and sibling sex mix, statistics

\begin{tabular}{|c|c|c|c|c|c|c|c|c|}
\hline $\begin{array}{c}\text { Fraction of } \\
\text { sample }\end{array}$ & \multicolumn{2}{|c|}{$\begin{array}{l}\text { Total } \\
\text { fertility }\end{array}$} & \multicolumn{2}{|c|}{$\begin{array}{l}\text { Fraction had } \\
\text { another child }\end{array}$} & \multicolumn{2}{|c|}{$\begin{array}{c}\text { Became } \\
\text { grandparent }\end{array}$} & \multicolumn{2}{|c|}{$\begin{array}{l}\text { Age became } \\
\text { grandparent }\end{array}$} \\
\hline All & Men & Women & Men & Women & Men & Women & Men & Women \\
\hline
\end{tabular}

Sibling mix:

\begin{tabular}{|c|c|c|c|c|c|c|c|c|c|}
\hline (1) Two girls & 0.242 & $\begin{array}{c}2.82 \\
(0.05)\end{array}$ & $\begin{array}{c}2.88 \\
(0.02)\end{array}$ & $\begin{array}{c}0.493 \\
(0.023)\end{array}$ & $\begin{array}{c}0.507 \\
(0.019)\end{array}$ & $\begin{array}{c}0.924 \\
(0.024)\end{array}$ & $\begin{array}{c}0.937 \\
(0.020)\end{array}$ & $\begin{array}{l}48.20 \\
(0.57)\end{array}$ & $\begin{array}{l}44.11 \\
(0.41)\end{array}$ \\
\hline (2) Other mix & 0.758 & $\begin{array}{c}2.76 \\
(0.03)\end{array}$ & $\begin{array}{c}2.80 \\
(0.04)\end{array}$ & $\begin{array}{c}0.458 \\
(0.013)\end{array}$ & $\begin{array}{c}0.463 \\
(0.011)\end{array}$ & $\begin{array}{c}0.924 \\
(0.013)\end{array}$ & $\begin{array}{c}0.919 \\
(0.012)\end{array}$ & $\begin{array}{l}49.19 \\
(0.28)\end{array}$ & $\begin{array}{l}46.29 \\
(0.24)\end{array}$ \\
\hline Two boys & 0.269 & 2.77 & 2.83 & 0.489 & 0.489 & 0.917 & 0.917 & 49.90 & 47.28 \\
\hline Other, excl. (1) & 0.490 & 2.80 & 2.82 & 0.458 & 0.469 & 0.862 & 0.869 & 48.61 & 45.19 \\
\hline $\operatorname{diff}(1)-(2)$ & & $\begin{array}{c}0.051 \\
(0.080)\end{array}$ & $\begin{array}{c}0.080 \\
(0.050)\end{array}$ & $\begin{array}{c}0.035 \\
(0.026)\end{array}$ & $\begin{array}{c}0.043 \\
(0.022)\end{array}$ & $\begin{array}{c}0.000 \\
(0.031)\end{array}$ & $\begin{array}{c}0.019 \\
(0.024)\end{array}$ & $\begin{array}{l}-0.98 \\
(0.63)\end{array}$ & $\begin{array}{l}-2.17 \\
(0.47)\end{array}$ \\
\hline p-val & & 0.35 & 0.10 & 0.18 & 0.05 & 0.99 & 0.43 & 0.12 & 0.00 \\
\hline Individuals: & 7,525 & 2,930 & 4,595 & 2,930 & 4,595 & 681 & 1,019 & 1,138 & 2,021 \\
\hline $\begin{array}{l}\text { First child: } \\
\text { (3) Girl }\end{array}$ & 0.478 & $\begin{array}{c}2.39 \\
(0.03)\end{array}$ & $\begin{array}{c}2.51 \\
(0.03)\end{array}$ & $\begin{array}{c}0.773 \\
(0.013)\end{array}$ & $\begin{array}{c}0.804 \\
(0.010)\end{array}$ & $\begin{array}{c}0.897 \\
(0.017)\end{array}$ & $\begin{array}{c}0.897 \\
(0.017)\end{array}$ & $\begin{array}{l}48.37 \\
(0.35)\end{array}$ & $\begin{array}{l}44.59 \\
(0.28)\end{array}$ \\
\hline (4) Boy & 0.522 & $\begin{array}{c}2.34 \\
(0.03)\end{array}$ & $\begin{array}{c}2.45 \\
(0.03)\end{array}$ & $\begin{array}{c}0.760 \\
(0.012)\end{array}$ & $\begin{array}{c}0.807 \\
(0.010)\end{array}$ & $\begin{array}{c}0.875 \\
(0.019)\end{array}$ & $\begin{array}{c}0.882 \\
(0.016)\end{array}$ & $\begin{array}{l}49.30 \\
(0.32)\end{array}$ & $\begin{array}{l}46.60 \\
(0.27)\end{array}$ \\
\hline $\operatorname{diff}(3)-(4)$ & & $\begin{array}{c}0.05 \\
(0.05)\end{array}$ & $\begin{array}{c}0.06 \\
(0.04)\end{array}$ & $\begin{array}{l}0.013 \\
(0.17)\end{array}$ & $\begin{array}{l}-0.003 \\
(0.015)\end{array}$ & $\begin{array}{c}0.022 \\
(0.026)\end{array}$ & $\begin{array}{c}0.016 \\
(0.024)\end{array}$ & $\begin{array}{l}-0.92 \\
(0.47)\end{array}$ & $\begin{array}{l}-2.01 \\
(0.39)\end{array}$ \\
\hline p-val & & 0.33 & 0.17 & 0.44 & 0.86 & 0.40 & 0.51 & 0.05 & 0.00 \\
\hline Individuals: & 8,964 & 3,701 & 5,263 & 3,701 & 5,263 & 781 & 1,120 & 1,250 & 2,195 \\
\hline
\end{tabular}

Notes: The table reports, by gender, means and standard errors of total, lifetime fertility, probability of having an additional child, probability of becoming a grandparent (for those born no later than 1940), and age one becomes a grandparent in the groups defined by, respectively, twogirls and girlfirst. PSID core sample, waves 1968-2011, individuals (Seniors, in Section 2) no older than 70 who have at least one child (Junior, in Section 2) who is 14 or older. Individual sampling weights are applied. The p-value refers to a t-test of the null hypothesis that the difference between the means is zero. 
Table 7: Fertility and grandparent status by gender of first child and sibling sex mix, regression

\begin{tabular}{ccccccc}
\hline \multirow{4}{*}{ twogirls } & \multicolumn{2}{c}{ Total fertility } & \multicolumn{2}{c}{ Had another child } & \multicolumn{2}{c}{ Age became grandparent } \\
\cline { 2 - 7 } & Men & Women & Men & Women & Men & Women \\
\cline { 2 - 7 } girlfirst & 0.030 & 0.018 & 0.008 & -0.002 & -1.318 & -1.802 \\
& $(0.030)$ & $(0.030)$ & $(0.011)$ & $(0.009)$ & $(0.329)$ & $(0.247)$ \\
& 0.059 & 0.035 & 0.036 & 0.024 & -1.077 & -1.768 \\
& $(0.038)$ & $(0.035)$ & $(0.017)$ & $(0.014)$ & $(0.393)$ & $(0.288)$ \\
\hline \hline
\end{tabular}

Notes: The table reports, by gender, the coefficients from a regression of total, lifetime fertility, indicator for whether one had an additional child, indicator for whether one becomes a grandparent, and age one becomes a grandparent, over $t$ wogirls and girlfirst. PSID core sample, waves 1968-2011, individuals (Seniors, in Section 2) no older than 70 who have at least one child (Junior, in Section 2) who is 14 or older. Age and year dummies are included as additional dependent variables. Family income in 1967 (y67 $i)$ is included as an additional independent variable to controls for unequal sampling probabilities in a regression framework (Solon et al. (2013)). Robust standard errors in parentheses, clustered at the individual level.

Table 8: First stage results

\begin{tabular}{lcccc}
\hline & $(1)$ & $(2)$ & $(3)$ & $(4)$ \\
\cline { 2 - 5 } & $g_{i t}$ & $g_{i t}$ & $g_{i t}$ & $g_{i t}$ \\
& men & women & men & women \\
\cline { 2 - 5 } twogirls $_{i}$ & 0.059 & 0.083 & & \\
girlfirst $i$ & $(0.015)$ & $(0.012)$ & & \\
& & & 0.067 & 0.090 \\
y67 $i$ & & & $(0.012)$ & $(0.010)$ \\
& & & & \\
Constant & -0.002 & -0.002 & -0.002 & -0.002 \\
& $(0.000)$ & $(0.000)$ & $(0.000)$ & $(0.000)$ \\
F-stat, excl. instrument & 0.143 & 0.046 & 0.088 & 0.014 \\
Fixed effects & $(0.083)$ & $(0.023)$ & $(0.068)$ & $(0.022)$ \\
Age dummies & & & & \\
Year dummies & No & No & No & No \\
& Yes & Yes & Yes & Yes \\
Observations & Yes & Yes & Yes & Yes \\
\hline \hline
\end{tabular}

Notes: First-stage estimates, i.e., effect of twogirls and girlfirst on the probability of being a grandparent at some point during the life cycle, conditional on being a parent. PSID core sample, waves 1968-2011, individuals (Seniors, in Section 2) no older than 70 who have at least one child (Junior, in Section 2) who is 14 or older. Covariate $y 67_{i}$ is family income in 1967 and controls for unequal sampling probabilities in a regression framework (Solon et al. (2013)). Robust standard errors in parentheses, clustered at the individual level. 
ble 10 shows that the second, stronger instrument, girl first, detects a negative effect of becoming a grandmother on the labor supply of employed women. The magnitude of the effect is about 380 hours per year. The intensive margin effect on employed men is much smaller, about 140 hours, but still imprecisely estimated. When using girl first, extensive margin estimates are positive and large for men. The overall labor supply effect is positive for men (about 100 hours) and a negative for women (230 hours). However, the associated standard errors are too large to draw reliable conclusions on extensive margin and overall labor supply effects.

Table 9: IV estimates. Instrument: twogirls (IV1)

\begin{tabular}{lcccccc}
\hline & $(1)$ & $(2)$ & $(3)$ & $(4)$ & $(5)$ & $(6)$ \\
\cline { 2 - 7 }$g_{i t}$ & $h_{i t}$ & $h_{i t}$ & $e_{i t}$ & $e_{i t}$ & $H_{i t}$ & $H_{i t}$ \\
& men & women & men & women & men & women \\
\cline { 2 - 7 }$y 67_{i}$ & -629.8 & -293.5 & 0.137 & -0.078 & -291.0 & -317.2 \\
& $(373.8)$ & $(230.9)$ & $(0.167)$ & $(0.151)$ & $(481.8)$ & $(315.7)$ \\
Constant & 0.6 & -0.9 & 0.001 & 0.001 & 2.5 & 0.6 \\
& $(0.7)$ & $(0.5)$ & $(0.000)$ & $(0.000)$ & $(0.9)$ & $(0.8)$ \\
& 1968.9 & 887.9 & 0.118 & -0.053 & 600.3 & -298.5 \\
Observations & 32,690 & 42,336 & 38,839 & 63,649 & 38,839 & 63,649 \\
Fixed effects & No & No & No & No & No & No \\
Age dummies & Yes & Yes & Yes & Yes & Yes & Yes \\
Year dummies & Yes & Yes & Yes & Yes & Yes & Yes \\
\hline \hline
\end{tabular}

Notes: Second-stage estimates from 2SLS estimates of Eq. 14, PSID core sample, waves 1968-2011, individuals (Seniors, in Section 2) no older than 70 who have at least one child (Junior, in Section 2) who is 14 or older. The dependent variables are, alternately, annual hours of work for pay conditional on being employed (i.e., excluding zero hours, $h_{i t}$ ), an employment dummy $\left(e_{i t}\right)$, and unconditional annual hours of work for pay (i.e., including zero hours, $\left.H_{i t}\right)$. The instrument is twogirls, as defined in Eq. 18. First-stage estimates are reported in Table 8. Covariate $y 67_{i}$ is family income in 1967 and controls for unequal sampling probabilities in a regression framework (Solon et al. (2013)). Robust standard errors in parentheses, clustered at the individual level.

In sum, our analysis identifies a significant negative effect of becoming a grandmother on employed women's labor supply: 380 hours per year. Such an effect is admittedly large, and stands in sharp contrast with the OLS and FE estimates - an order of magnitude larger. Furthermore, for women the IV estimate has the opposite sign than the OLS and FE ones. We offer two explanations.

First, the magnitude reflects the local nature of the IV estimate. That is, the local average treatment effect we identify differs from the average treatment effect of interest. Specifically, it is larger in absolute value. The reason is that under the maintained exclusion restriction assumptions, the instruments allow us to identify the effect of becoming a grandparent on the labor supply of parents whose first two children are girls and with a first-born girl, respectively. However, it is a well-documented fact that maternal grandmothers have different access to the grandchildren. For instance, Compton and Pollak (2014) show that maternal grandmothers do more grandparenting than paternal ones. Because at each birth the probability of having a girl is $50 \%$, we can divide our 
Table 10: IV estimates. Instrument: girl first (IV2)

\begin{tabular}{lcccccc}
\hline & $(1)$ & $(2)$ & $(3)$ & $(4)$ & $(5)$ & $(6)$ \\
\cline { 2 - 7 } & $h_{i t}$ & $h_{i t}$ & $e_{i t}$ & $e_{i t}$ & $H_{i t}$ & $H_{i t}$ \\
& men & women & men & women & men & women \\
\cline { 2 - 7 }$g_{i t}$ & -142.2 & -383.7 & 0.106 & 0.011 & 107.2 & -231.4 \\
& $(228.7)$ & $(170.3)$ & $(0.119)$ & $(0.112)$ & $(342.4)$ & $(232.6)$ \\
$y 67_{i}$ & 1.4 & -1.0 & 0.001 & 0.001 & 3.2 & 0.8 \\
& $(0.4)$ & $(0.4)$ & $(0.000)$ & $(0.000)$ & $(0.7)$ & $(0.6)$ \\
Constant & 1413.0 & 998.4 & 0.156 & -0.152 & 189.7 & -403.3 \\
& $(270.0)$ & $(223.7)$ & $(0.130)$ & $(0.126)$ & $(367.5)$ & $(259.1)$ \\
& & & & & & \\
Observations & 37,722 & 48,331 & 44,998 & 71,965 & 44,998 & 71,965 \\
Fixed effects & No & No & No & No & No & No \\
Age dummies & Yes & Yes & Yes & Yes & Yes & Yes \\
Year dummies & Yes & Yes & Yes & Yes & Yes & Yes \\
\hline \hline
\end{tabular}

Notes: Second-stage estimates from 2SLS estimates of Eq. 14, PSID core sample, waves 1968-2011, individuals (Seniors, in Section 2) no older than 70 who have at least one child (Junior, in Section 2) who is 14 or older. The dependent variables are, alternately, annual hours of work for pay conditional on being employed (i.e., excluding zero hours, $h_{i t}$ ), an employment dummy $\left(e_{i t}\right)$, and unconditional annual hours of work for pay (i.e., including zero hours, $\left.H_{i t}\right)$. The instrument is girlfirst, as defined in Eq. 19. First-stage estimates are reported in Table 8. Covariate $y 67_{i}$ is family income in 1967 and controls for unequal sampling probabilities in a regression framework (Solon et al. (2013)). Robust standard errors in parentheses, clustered at the individual level. 
estimates by 2 , and thus identify a lower bound for the average effect of interest. ${ }^{18}$ Therefore, the girlfirst instrument identifies, in particular, a significant lower bound of about 190 hours on the labor supply of an employed woman after she becomes a grandmother.

Second, as discussed above, the instrument is supposed to take care of possible bias arising from reverse causality. In particular, the possibility that a future, anticipated reduction in Senior's labor supply reduces Junior's expected cost of child bearing and so increases the probability that Senior becomes a grandparent. If this is the case and if the instrument identifies the true effect of becoming a grandparent, then the IV estimates may well invert the sign of the OLS and the FE ones, which would both be affected by simultaneity bias. A simple example illustrates this point. Let's consider hours conditional on employment in a univariate two-equation model with perfect forecast about Senior's labor supply. The first equation determines hours as a function of the grandparent status, and the second equation is a linear probability model for the likelihood of becoming a grandparent as a function of the perfectly forecast variation in hours between period $t$ and period $t+1, \Delta h_{i t} \equiv h_{i t+1}-h_{i t}$. For simplicity, we omit the constant:

$$
\begin{aligned}
h_{i t} & =\beta g_{i t}+\varepsilon_{i t} \\
g_{i t} & =b \Delta h_{i t}+e_{i t},
\end{aligned}
$$

where $b<0$ (i.e., the higher the expected reduction in hours, the higher the probability of becoming a grandparent). Solving the system, assuming for simplicity that $\varepsilon_{i t}, e_{i t}$, and $h_{i t+1}$ are pairwise uncorrelated, assuming that $\varepsilon_{i t}$ and $e_{i t}$ are zero-mean, and normalizing the variance of $\varepsilon_{i t}$ to 1 , then if one runs a regression of $h_{i t}$ over $g_{i t}$, one obtains the linear projection coefficient:

$$
\frac{\mathbb{E}\left(h_{i t+1} g_{i t}\right)}{\mathbb{E}\left(g_{i t}^{2}\right)}=\frac{\beta b^{2} \mathbb{E}\left(h_{i t+1}^{2}\right)+\beta-b}{b^{2} \mathbb{E}\left(h_{i t+1}^{2}\right)+b^{2} \operatorname{var}\left(\varepsilon_{i t}\right)+1},
$$

which of course reduces to the true causal effect $\beta$ if $b=0$, i.e., if there is no simultaneity bias. It is easy to check that for all $b<0$ (but not for all $b>0$ ), in fact, the linear projection coefficient in Eq. 22 is above $\beta$ (and the more so the higher the absolute value of $b$ ), like our OLS and FE coefficients are above the IV ones.

The intution is the following. Grandparenthood is an absorbing state, i.e., $g_{i t}$ switches to and remains at 1 when one becomes a grandparent. If one ignores Eq. 21 then, using the terminology of Section 2, the more Senior's prospective reduction in labor supply increase the likelihood that Junior produces Baby, the more the OLS and the FE estimators incorrectly associate a higher value of current labor supply when $g_{i t}$ switches to 1 to the switch itself rather than to the prospective larger fall in labor supply which is one of the causes of the switch. ${ }^{19}$

\footnotetext{
18 This is obvious for the girlfirst instrument. For the twogirls instruments, suppose the effect for those with two girls is 1 . These are $25 \%$ of the total. Then the effect for those with one boy and one girl is, at worst, 0.5 - these are $50 \%$ of the total - and the effect for those with two boys is, at worst, zero- these are $25 \%$ of the total. The weighted average is, again, $1 / 2$.

19 Another way to see this is to notice that, because $b<0$, if grandparenting did not affect labor supply (i.e., if $\beta=0$ ) then the linear projection coefficient would be strictly positive-although probably quite small.
} 


\subsubsection{Addressing IV pitfalls}

As mentioned above, a major concern with our preferred instrument, girlfirst, is the possible violation of the exclusion restriction, because a first-born girl may affect outcomes potentially related to labor supply at different stages of the life cycle. One such effect is own fertility, which is one of rationales of the instrument itself. If a first-born girl induces higher fertility and the latter has a persistent effect on labor supply, then the instrument affects the outcome via a channel (own fertility) other than the probability of becoming a grandparent. However, the evidence does not support this scenario. Although young children do have a negative effect on the labor supply of young mothers, Bronars and Grogger (1994), Jacobsen et al. (1999), and Rondinelli and Zizza (2010) all find that this effect is non-persistent. That is, higher fertility seems to be unrelated to women's labor supply after age 40, when the grandparenting "treatment" may kick in.

Another well-documented effect of a first-born girl vs. first-born boy is reduced marital stability, a fact first noted by Morgan, Lye, and Condran (1988). ${ }^{20}$ Therefore, the gender of one's first child may affect labor supply late in the working life via marital history. However, in this case we can establish the sign of the ensuing bias. It turns out that such bias, if present, only makes our lower bounds even more conservative. To illustrate, consider the univariate version of the empirical model in Eq. 14, with marital stability as an omitted variable:

$$
\begin{aligned}
L_{i t} & =\alpha+\beta g_{i t}+\varepsilon_{i t} \\
\varepsilon_{i t} & =\gamma \cdot \text { divorced }_{i t}+v_{i t}
\end{aligned}
$$

where divorced $_{i t}$ is a dummy variable assuming value 1 if individual $i$ is divorced or separated at time $t$, and zero otherwise. Johnson and Skinner (1986) and Bedard and Deschenes (2005) show that divorced $d_{i t}$ is associated with higher female labor supply. We also see this fact in our own final sample, where employed women who are divorced or separated work 249 hours (s.e. 10.9) more than those who are not. The corresponding association with the employment rate is 13.5 percentage points (s.e. 0.06). Therefore, for these women $\gamma>0$ in Eq. 24. Now suppose we use girlfirst $t_{i}$ as an instrument for $g_{i t}$ in Eq. 23, and that $\operatorname{cov}\left(\right.$ girlfirst $\left._{i}, v_{i t}\right)=0$. However, given the evidence on the effect of a first-born girl on marital stability, $\operatorname{cov}\left(\right.$ girlfirst $_{i}$, divorce $\left._{i t}\right)=\rho>0$. This implies that $\operatorname{cov}\left(\right.$ girlfirst $\left._{i}, \varepsilon_{i t}\right)=\gamma \rho>0$, and the exclusion restriction is violated. The probability limit of the IV estimator in this case is:

$$
\operatorname{plim} \hat{\beta}_{I V}=\beta+\frac{\gamma \rho}{\operatorname{cov}\left(\text { girlfirst }_{i}, g_{i t}\right)} .
$$

Given that $\gamma \rho>0$, the bias term is positive because our first-stage implies $\operatorname{cov}\left(\right.$ girl first $\left._{i}, g_{i t}\right)>$ 0 . Therefore, for women in our final sample $\hat{\beta}_{I V}$ is a lower bound (in absolute value, given that this estimate is negative) of the true effect of interest, $\beta$. This line of reasoning, of course, extends to the multivariate model we employed, and to other possible channels that are similarly related to labor supply and gender of one's first child. ${ }^{21}$ For men, the sign of $\gamma$ is actually negative in

\footnotetext{
${ }^{20}$ Using data from the June 1980 CPS, they find that "For couples with one child, [...] the risk of disruption is $9 \%$ higher for those with a daughter than for those with a son" (p. 115).

${ }^{21}$ For instance, Ichino et al. (2013) report that a first-born girl increases the health of one's offspring and the latter, in turn, has a positive effect on mothers' labor supply.
} 
our final sample, where employed men who are divorced or separated work 76 hours per year (s.e. 17) less than those who are not, and all divorced or separated men are 7.5 percentage points (s.e. 0.08) less likely to be employed than their counterparts in a different marital status. The same kind of reasoning used for women implies that the effect of becoming a grandparent on men's labor supply is actually smaller, in absolute value, than the one reported above, and can potentially be of opposite sign. This is a good reason for interpreting with much caution our results for men.

Of course, contrary to the example in Eq. 23-Eq. 24, there may be many omitted variables that correlate in different ways with the gender of one's first child. What if we take as many potential omitted variables as possible out of the error term? We next check the sensitivity of the IV results obtained with our preferred instrument to the inclusion of additional individual covariates. The downside of this check is that we are including on the RHS more possibly endogenous variables which we cannot instrument. Table 11 reports the results. Comparing this with Table 10, we see that the effect on employed women's hours is virtually unaffected. The point estimates for employed men and women's participation move upward, but they remain statistically indistinguishable from zero.

\section{Extensions}

In this Section we extend the baseline instrumental variable analysis by briefly exploring several margins of heterogeneity. This allows us to "test" the plausibility of our results, and to gain a better understanding of the underlying mechanisms. Henceforth, we restrict to our preferred instrument, girl first. A word of caution is in order, though: exploring heterogeneity means conditioning on (or splitting the sample along) variables that are potentially endogenous in a richer labor supply model. Therefore, the following results should be interpreted with care. In particular, we do not claim that all of these heterogeneous effects are causal. Nonetheless, the results below are informative and indicate promising avenues for future research.

\subsection{Geographic distance}

A first, important margin is the geographic proximity between grandparents and grandchildren. A priori, one cannot tell what the effect on labor supply should be. Although grandparents who live closer to their grandchildren may transfer more time because the unit transfer cost is lower, those who live farther away from them need more traveling time per unit transferred.

We exploit information on proximity at the county and Census tract level. Specifically, we construct proximity dummy variables at these two levels of aggregation that assume value 1 if individual $i$ lives, in year $t$, in the same county (samecounty ${ }_{i t}$ ) or tract (sametract sit $_{\text {) }}$ of at least one grandchild, and zero otherwise. Of course these dummies are set to zero for those who have no grandchildren. According to these indicators, and after applying sampling weights, $65.4 \%$ and $41.3 \%$ of all grandparents in our final sample live in the same county or Census tract, respectively, of at least one grandchild. These figures are in line with the findings of Choi (2009), who documents the pattern of proximity to one's mother by age in the U.S. using the PSID, and are also consistent with the findings of Compton and Pollak (2013) in the NSFH: these data show that the median distance between married women in the U.S. and their mothers is 20 miles, with $25 \%$ of them living within 5 miles of their mothers. One's location is obviously endogenous to labor supply, so 
Table 11: IV (girlfirst) estimates, with additional covariates

\begin{tabular}{|c|c|c|c|c|c|c|}
\hline & (1) & $(2)$ & (3) & (4) & $(5)$ & $(6)$ \\
\hline & $\begin{array}{c}h_{i t} \\
\text { men }\end{array}$ & $\begin{array}{c}\quad h_{i t} \\
\text { women }\end{array}$ & $\begin{array}{c}e_{i t} \\
\text { men }\end{array}$ & $\begin{array}{c}e_{i t} \\
\text { women }\end{array}$ & $\begin{array}{c}H_{i t} \\
\text { men }\end{array}$ & $\begin{array}{c}H_{i t} \\
\text { women }\end{array}$ \\
\hline$g_{i t}$ & $\begin{array}{c}-46.7 \\
(231.3)\end{array}$ & $\begin{array}{l}-377.5 \\
(172.5)\end{array}$ & $\begin{array}{c}0.125 \\
(0.098)\end{array}$ & $\begin{array}{c}0.120 \\
(0.106)\end{array}$ & $\begin{array}{c}193.9 \\
(292.5)\end{array}$ & $\begin{array}{c}-75.9 \\
(223.8)\end{array}$ \\
\hline$y 67_{i}$ & $\begin{array}{c}0.6 \\
(0.3)\end{array}$ & $\begin{array}{l}-0.2 \\
(0.3)\end{array}$ & $\begin{array}{c}0.000 \\
(0.000)\end{array}$ & $\begin{array}{c}0.000 \\
(0.000)\end{array}$ & $\begin{array}{c}1.1 \\
(0.4)\end{array}$ & $\begin{array}{c}0.1 \\
(0.3)\end{array}$ \\
\hline Divorced or separated & $\begin{array}{l}-78.2 \\
(23.2)\end{array}$ & $\begin{array}{l}174.1 \\
(16.6)\end{array}$ & $\begin{array}{l}-0.067 \\
(0.011)\end{array}$ & $\begin{array}{c}0.069 \\
(0.010)\end{array}$ & $\begin{array}{l}-198.7 \\
(29.2)\end{array}$ & $\begin{array}{l}234.8 \\
(22.1)\end{array}$ \\
\hline Widowed & $\begin{array}{l}-169.4 \\
(44.1)\end{array}$ & $\begin{array}{c}31.8 \\
(30.2)\end{array}$ & $\begin{array}{c}-0.057 \\
(0.024)\end{array}$ & $\begin{array}{c}0.031 \\
(0.017)\end{array}$ & $\begin{array}{l}-198.7 \\
(51.9)\end{array}$ & $\begin{array}{c}72.2 \\
(32.6)\end{array}$ \\
\hline White & $\begin{array}{c}69.9 \\
(40.5)\end{array}$ & $\begin{array}{l}-71.3 \\
(43.0)\end{array}$ & $\begin{array}{l}-0.003 \\
(0.021)\end{array}$ & $\begin{array}{c}0.008 \\
(0.024)\end{array}$ & $\begin{array}{c}49.6 \\
(52.1)\end{array}$ & $\begin{array}{l}-18.4 \\
(53.7)\end{array}$ \\
\hline Black & $\begin{array}{l}-41.9 \\
(42.2)\end{array}$ & $\begin{array}{c}7.6 \\
(45.5)\end{array}$ & $\begin{array}{l}-0.024 \\
(0.022)\end{array}$ & $\begin{array}{c}-0.001 \\
(0.026)\end{array}$ & $\begin{array}{l}-79.2 \\
(54.2)\end{array}$ & $\begin{array}{c}19.0 \\
(57.4)\end{array}$ \\
\hline Less than high school & $\begin{array}{l}-66.9 \\
(28.3)\end{array}$ & $\begin{array}{l}-61.4 \\
(30.6)\end{array}$ & $\begin{array}{l}-0.050 \\
(0.013)\end{array}$ & $\begin{array}{l}-0.168 \\
(0.018)\end{array}$ & $\begin{array}{l}-146.3 \\
(35.1)\end{array}$ & $\begin{array}{l}-300.4 \\
(36.5)\end{array}$ \\
\hline College degree & $\begin{array}{c}49.6 \\
(36.4)\end{array}$ & $\begin{array}{l}-62.2 \\
(36.2)\end{array}$ & $\begin{array}{c}0.064 \\
(0.015)\end{array}$ & $\begin{array}{c}0.123 \\
(0.021)\end{array}$ & $\begin{array}{l}169.3 \\
(46.2)\end{array}$ & $\begin{array}{l}157.2 \\
(46.3)\end{array}$ \\
\hline Non-labor income ('000) & $\begin{array}{l}-0.2 \\
(0.1)\end{array}$ & $\begin{array}{l}-0.4 \\
(0.1)\end{array}$ & $\begin{array}{l}-0.000 \\
(0.000)\end{array}$ & $\begin{array}{l}-0.000 \\
(0.000)\end{array}$ & $\begin{array}{l}-0.6 \\
(0.1)\end{array}$ & $\begin{array}{l}-0.8 \\
(0.1)\end{array}$ \\
\hline Disability & $\begin{array}{l}-263.9 \\
(20.5)\end{array}$ & $\begin{array}{l}-212.8 \\
(17.9)\end{array}$ & $\begin{array}{l}-0.284 \\
(0.012)\end{array}$ & $\begin{array}{l}-0.256 \\
(0.010)\end{array}$ & $\begin{array}{l}-737.9 \\
(27.4)\end{array}$ & $\begin{array}{l}-524.0 \\
(19.3)\end{array}$ \\
\hline Number own children & $\begin{array}{c}4.8 \\
(19.8)\end{array}$ & $\begin{array}{c}24.4 \\
(14.5)\end{array}$ & $\begin{array}{c}-0.014 \\
(0.008)\end{array}$ & $\begin{array}{l}-0.019 \\
(0.007)\end{array}$ & $\begin{array}{l}-21.7 \\
(23.8)\end{array}$ & $\begin{array}{l}-14.6 \\
(15.4)\end{array}$ \\
\hline Number children in household & $\begin{array}{c}-6.4 \\
(15.5)\end{array}$ & $\begin{array}{l}-73.0 \\
(9.7)\end{array}$ & $\begin{array}{c}0.002 \\
(0.006)\end{array}$ & $\begin{array}{l}-0.023 \\
(0.005)\end{array}$ & $\begin{array}{c}-3.4 \\
(18.4)\end{array}$ & $\begin{array}{l}-81.3 \\
(10.5)\end{array}$ \\
\hline Relocated & $\begin{array}{l}-69.4 \\
(15.6)\end{array}$ & $\begin{array}{l}-41.2 \\
(14.3)\end{array}$ & $\begin{array}{l}-0.022 \\
(0.006)\end{array}$ & $\begin{array}{l}-0.029 \\
(0.008)\end{array}$ & $\begin{array}{l}-101.3 \\
(18.1)\end{array}$ & $\begin{array}{l}-78.9 \\
(16.4)\end{array}$ \\
\hline Constant & $\begin{array}{l}1,289.4 \\
(193.7)\end{array}$ & $\begin{array}{l}1,414.0 \\
(148.2)\end{array}$ & $\begin{array}{c}0.308 \\
(0.073)\end{array}$ & $\begin{array}{c}0.242 \\
(0.079)\end{array}$ & $\begin{array}{c}433.0 \\
(202.0)\end{array}$ & $\begin{array}{c}557.8 \\
(163.5)\end{array}$ \\
\hline Observations & 36,272 & 44,164 & 43,177 & 64,833 & 43,177 & 64,833 \\
\hline Fixed effects & No & No & No & No & No & No \\
\hline Age dummies & Yes & Yes & Yes & Yes & Yes & Yes \\
\hline Year dummies & Yes & Yes & Yes & Yes & Yes & Yes \\
\hline
\end{tabular}

Notes: Second-stage estimates from 2SLS estimates of Eq. 14, PSID core sample, waves 1968-2011, individuals (Seniors, in Section 2) no older than 70 who have at least one child (Junior, in Section 2) who is 14 or older. The dependent variables are, alternately, annual hours of work for pay conditional on being employed (i.e., excluding zero hours, $h_{i t}$ ), an employment dummy $\left(e_{i t}\right)$, and unconditional annual hours of work for pay (i.e., including zero hours, $\left.H_{i t}\right)$. The instrument is girlfirst, as defined in Eq. 19. First-stage estimates are reported in Table 8. Covariate $y 67_{i}$ is family income in 1967 and controls for unequal sampling probabilities in a regression framework (Solon et al. (2013)). Robust standard errors in parentheses, clustered at the individual level. 
the previous warning applies. ${ }^{22}$ We interact these distance indicators with the explanatory variable of interest, $g_{i t}$, and we instrument the interacted variable with the analogous interaction with the instrument. For instance, $g_{i t} \times$ samecount $_{i t}$ is instrumented with girl first ${ }_{i} \times$ samecount $_{i t}$.

The results are reported in Table 12. For employed women, there is a baseline negative effect of about 185 (about 90, in lower bound) hours, and an additional negative effect of about 205 (about 100, in lower bound) and 260 (about 130, in lower bound) hours for grandmothers living in the same county or Census tract of at least one grandchild, respectively. Therefore, the average effect identified in section 3.3.2 is mostly driven by these short-distance grandmothers. This goes in the direction one expects, i.e., prevalence of the "proximity effect" over a possible "traveling time effect". For employed men, instead, the point estimates (which are now a bit more precise) suggest that distance is irrelevant. Interestingly, the extensive margin effect for women is about +3 percentage points if living far away, but 2.2 percentage point less than this if living closer. Unfortunately, standard errors are again too large to draw any reliable conclusion about this margin.

\subsection{Number of grandchildren}

So far we have looked at the effect of being a grandparent vs. not being one. That is, we have focused on the "extensive margin" of grandparenting. An obvious question is whether there is an "intensive margin" effect. That is, conditional on being a grandparent, does the number of grandchildren play a role, too? The answer is again not obvious, because there are economies of scale in grandparenting: one can take care of, say, two, three, or four grandchildren employing roughly the same amount of time it takes to take care of one. On the other hand, the intensive margin may matter if one has several grandchildren living in different households.

To investigate this question, we interact $g_{i t}$ with the number of grandchildren individual $i$ has in year $t$ (ngchildren $\left._{i t}\right)$, using girl first ${ }_{i} \times$ ngchildren $_{i t}$ as an additional instrument. Therefore, the sum of the coefficients on girlfirst ${ }_{i}$ and girl first $_{i} \times$ ngchildren $_{i t}$ is the grandparenting "extensive margin" effect, and the coefficient on the latter is the "intensive margin" effect under the assumption that this is linear in the number of grandchildren. Table 13 reports the results. This table shows that, if anything, the grandparenting "intensive margin" is small and positive. Virtually all of the labor supply adjustment of working grandmothers occurs when they first have grandchildren. Taken at face values, these point estimates indicate, for these women, an average reduction of 475 (about 240, in lower bound) hours when they become grandmothers, which then become the 380 (190, in lower bound) hours of Table 11 when more grandchildren appear.

\subsection{Years since becoming a grandparent and age}

The previous result about the predominance of the grandparenting "extensive margin" suggests the importance of looking at how the labor supply effect we identify unfolds over time after one first becomes a grandparent. In other words, we ask the following question: how does such effect varies with the number of years since one first became a grandparent? This is also a convenient way of checking another margin of heterogeneity, namely having young vs. older grandchildren-

\footnotetext{
22 However, Compton and Pollak (2014) argue on the basis of exogenous shocks to distance between grandmothers and grandchildren generated by the relocation of "military households" that the bias from endogenous location is probably small.
} 
Table 12: IV estimates. Effect of distance

\begin{tabular}{|c|c|c|c|c|c|c|}
\hline & (1) & (2) & (3) & (4) & (5) & (6) \\
\hline & $\begin{array}{c}h_{i t} \\
\text { men }\end{array}$ & $\begin{array}{c}h_{i t} \\
\text { women }\end{array}$ & $\begin{array}{c}e_{i t} \\
\text { men }\end{array}$ & $\begin{array}{c}e_{i t} \\
\text { women }\end{array}$ & $\begin{array}{c}H_{i t} \\
\text { men }\end{array}$ & $\begin{array}{c}H_{i t} \\
\text { women }\end{array}$ \\
\hline \multirow{2}{*}{$g_{i t}$} & -125.2 & -184.4 & 0.033 & 0.034 & -37.6 & -78.3 \\
\hline & (109.9) & $(91.2)$ & $(0.062)$ & $(0.065)$ & (169.9) & (134.9) \\
\hline \multirow{2}{*}{$g_{i t} \times$ samecount $_{i t}$} & -18.1 & -206.2 & 0.073 & -0.022 & 143.6 & -148.0 \\
\hline & (137.5) & (91.3) & $(0.063)$ & $(0.051)$ & (182.6) & (104.8) \\
\hline \multirow{2}{*}{$y 67_{i}$} & 1.4 & -1.0 & 0.001 & 0.001 & 3.2 & 0.8 \\
\hline & $(0.4)$ & $(0.4)$ & $(0.000)$ & $(0.000)$ & $(0.6)$ & $(0.6)$ \\
\hline \multirow[t]{2}{*}{ Constant } & $1,408.7$ & 937.2 & 0.181 & -0.160 & 239.5 & -457.7 \\
\hline & (242.9) & (202.9) & $(0.110)$ & $(0.110)$ & (308.0) & $(224.0)$ \\
\hline Observations & 37,722 & 48,331 & 44,998 & 71,965 & 44,998 & 71,965 \\
\hline Fixed effects & No & No & No & No & No & No \\
\hline Age dummies & Yes & Yes & Yes & Yes & Yes & Yes \\
\hline \multirow[t]{4}{*}{ Year dummies } & Yes & Yes & Yes & Yes & Yes & Yes \\
\hline & (7) & (8) & (9) & (10) & (11) & (12) \\
\hline & $h_{i t}$ & $h_{i t}$ & $e_{i t}$ & $e_{i t}$ & $H_{i t}$ & $H_{i t}$ \\
\hline & men & women & men & women & men & women \\
\hline \multirow{2}{*}{$g_{i t}$} & -154.2 & -183.9 & 0.033 & 0.029 & -61.6 & -87.1 \\
\hline & $(101.2)$ & $(85.2)$ & $(0.055)$ & $(0.062)$ & (153.9) & $(128.1)$ \\
\hline \multirow{2}{*}{$g_{i t} \times$ sametract $_{i t}$} & 16.3 & -262.3 & 0.089 & -0.022 & 205.4 & -173.4 \\
\hline & (181.3) & (117.9) & $(0.082)$ & $(0.063)$ & (236.9) & (131.7) \\
\hline \multirow{2}{*}{$y 67_{i}$} & 1.4 & -1.1 & 0.001 & 0.001 & 3.2 & 0.8 \\
\hline & $(0.4)$ & $(0.4)$ & $(0.000)$ & $(0.000)$ & $(0.7)$ & $(0.6)$ \\
\hline \multirow[t]{2}{*}{ Constant } & $1,417.5$ & 923.5 & 0.190 & -0.160 & 268.1 & -471.3 \\
\hline & (227.8) & (198.9) & $(0.101)$ & $(0.103)$ & (280.9) & (210.2) \\
\hline Observations & 37,722 & 48,331 & 44,998 & 71,965 & 44,998 & 71,965 \\
\hline Fixed effects & No & No & No & No & No & No \\
\hline Age dummies & Yes & Yes & Yes & Yes & Yes & Yes \\
\hline Year dummies & Yes & Yes & Yes & Yes & Yes & Yes \\
\hline
\end{tabular}

Notes: 2SLS estimates, PSID core sample, waves 1968-2011, individuals (Seniors, in Section 2) no older than 70 who have at least one child (Junior, in Section 2) who is 14 or older. The dependent variables are, alternately, annual hours of work for pay conditional on being employed (i.e., excluding zero hours, $h_{i t}$ ), an employment dummy $\left(e_{i t}\right)$, and unconditional annual hours of work for pay (i.e., including zero hours, $H_{i t}$ ); samecount $y_{i t}$ is a dummy that assume value 1 if individual $i$ lives, in year $t$, in the same county of at least one grandchild, and zero otherwise, and similarly for sametract $_{i t}$ at the Census tract level. The instruments are girlfirst, as defined in Eq. 19, and girl first $t_{i} \times$ samecount $_{i t}$ and girlfirst $t_{i} \times$ sametract $_{i t}$, respectively. Covariate $y 67_{i}$ is family income in 1967 and controls for unequal sampling probabilities in a regression framework (Solon et al. (2013)). Robust standard errors in parentheses, clustered at the individual level. 
Table 13: IV estimates. Grandparenting "intensive" and "extensive" margins

\begin{tabular}{lcccccc}
\hline & $(1)$ & $(2)$ & $(3)$ & $(4)$ & $(5)$ & $(6)$ \\
\cline { 2 - 7 }$g_{i t}$ & $h_{i t}$ & $h_{i t}$ & $e_{i t}$ & $e_{i t}$ & $H_{i t}$ & $H_{i t}$ \\
& men & women & men & women & men & women \\
\cline { 2 - 7 }$g_{i t} \times$ ngchildren $_{i t}$ & -178.3 & -525.6 & 0.199 & 0.076 & 267.9 & -192.7 \\
& $(354.6)$ & $(256.3)$ & $(0.172)$ & $(0.148)$ & $(494.8)$ & $(310.3)$ \\
$y 67_{i}$ & $(51.1)$ & 50.5 & -0.032 & -0.022 & -55.8 & -13.0 \\
& 1.5 & -0.9 & 0.001 & 0.001 & 3.1 & 0.7 \\
Constant & $(0.3)$ & $(0.4)$ & $(0.000)$ & $(0.000)$ & $(0.6)$ & $(0.5)$ \\
& $1,377.8$ & 825.8 & 0.234 & -0.077 & 325.8 & -359.4 \\
& $(176.0)$ & $(149.5)$ & $(0.090)$ & $(0.088)$ & $(248.0)$ & $(176.6)$ \\
Observations & 37,722 & 48,331 & 44,998 & 71,965 & 44,998 & 71,965 \\
Fixed effects & No & No & No & No & No & No \\
Age dummies & Yes & Yes & Yes & Yes & Yes & Yes \\
Year dummies & Yes & Yes & Yes & Yes & Yes & Yes \\
\hline \hline
\end{tabular}

Notes: 2SLS estimates, PSID core sample, waves 1968-2011, individuals (Seniors, in Section 2) no older than 70 who have at least one child (Junior, in Section 2) who is 14 or older. The dependent variables are, alternately, annual hours of work for pay conditional on being employed (i.e., excluding zero hours, $\left.h_{i t}\right)$, an employment dummy $\left(e_{i t}\right)$, and unconditional annual hours of work for pay (i.e., including zero hours, $H_{i t}$ ); ngchildren $_{i t}$ is the number of grandchildren individual $i$ has in year $t$. The instruments are girlfirst, as defined in Eq. 19, and girl first ${ }_{i} \times$ ngchildren $_{i t}$. Covariate $y 67_{i}$ is family income in 1967 and controls for unequal sampling probabilities in a regression framework (Solon et al. (2013)). Robust standard errors in parentheses, clustered at the individual level. 
presumably, the incidence of young grandchildren is higher during the first years since one first became a grandparent.

To perform this exercise, we modify the grandparent indicator $g_{i t}$ to reflect "grandparenting lags". That is, we define indicators $g_{\text {it } \ell}$ for lags $\ell=1, \ldots, 13$, where the lag is the number of years since one first became a grandparent. Indicator $g_{i t \ell}$ assumes value zero until (if ever) one becomes a grandparent, then assumes value 1 if in year $t$ one has grandchildren but no more than $l$ years elapsed since one became a grandparent, and then assumes value zero again. That is, contrary to $g_{i t}, g_{i t \ell}$ is not an absorbing indicator. Figure 3 illustrates how $g_{i t \ell}$ is constructed. We summarize in Figure 4 the results for hours of working grandparents. ${ }^{23}$ This picture shows that for working women hours drop substantially during the first years since becoming grandmothers, and then converge to the point estimate reported Table 10, represented in the picture by a horizontal red line. For working men, if there is an effect, this materialized later on-the point estimate is effectively zero during the first few years since becoming a grandfather.

Figure 3: Construction of indicator $g_{i t \ell}$

\begin{tabular}{|c|c|c|c|c|c|c|c|c|c|c|}
\hline \multirow{2}{*}{$\begin{array}{c}\mathrm{Lag} \\
(\ell)\end{array}$} & & \multicolumn{9}{|c|}{ Years since $i$ became a grandparent } \\
\hline & & .. & -2 & -1 & 0 & 1 & 2 & 3 & 4 & .. \\
\hline 1 & $g_{i t 1}=$ & 0 & 0 & 0 & 0 & 1 & 0 & 0 & 0 & 0 \\
\hline 2 & $g_{i t 2}=$ & 0 & 0 & 0 & 0 & 1 & 1 & 0 & 0 & 0 \\
\hline 3 & $g_{i t 3}=$ & 0 & 0 & 0 & 0 & 1 & 1 & 1 & 0 & 0 \\
\hline 4 & $g_{i t 4}=$ & 0 & 0 & 0 & 0 & 1 & 1 & 1 & 1 & 0 \\
\hline$\vdots$ & $g_{\text {it } \ell}=$ & 0 & 0 & 0 & 0 & 1 & 1 & 1 & 1 & 1 \\
\hline
\end{tabular}

Notes: The figure illustrates the construction of indicator $g_{i t}$. For given year $t$ and given that individual $i$ becomes a grandparent in year $\tau, g_{\text {it } \ell}$ assumes value 0 until year $\tau$, and then assumes value 1 for as many years as the lag $\ell$ indicates.

A related but distinct question is how the effect of interest varies with grandparents' age. To gauge this margin of heterogeneity we replace $g_{i t}$ with the interaction between $g_{i t}$ and age $\left(g_{i t} \times\right.$ $a g e_{i t}$ ), using girlfirst $_{i} \times a g e_{i t}$ as an instrument. As reported in Table 14, the negative effect is stronger, for working grandparents, the older they are. For employed women, in particular, the average reduction increases by about 100 hours (50 hours, in lower bound) every 10 years. We employed alternative specifications where $g_{i t}$ is interacted with polynomials in age, but these do not produce evidence of nonlinearities in age, and so are not reported here.

\subsection{Quantiles of the hours distribution}

Another interesting question is whether there are different effects at different quantiles of the distribution of hours conditional on employment. This is also a convenient way of checking how, in practice, employed grandparents adjust labor supply in response to the appearance of grandchildren. We answer this question by employing the instrumental variable quantile regression method developed by Chernozhukov and Hansen (2006). ${ }^{24}$

\footnotetext{
${ }^{23}$ The analogous estimates for the extensive margin turn out to be too noisy to allow any reliable speculation

${ }^{24}$ We implement this regression with the ivqreg Stata code written by Kwak (2010).
} 
Figure 4: IV estimates by number of years since becoming a grandparent
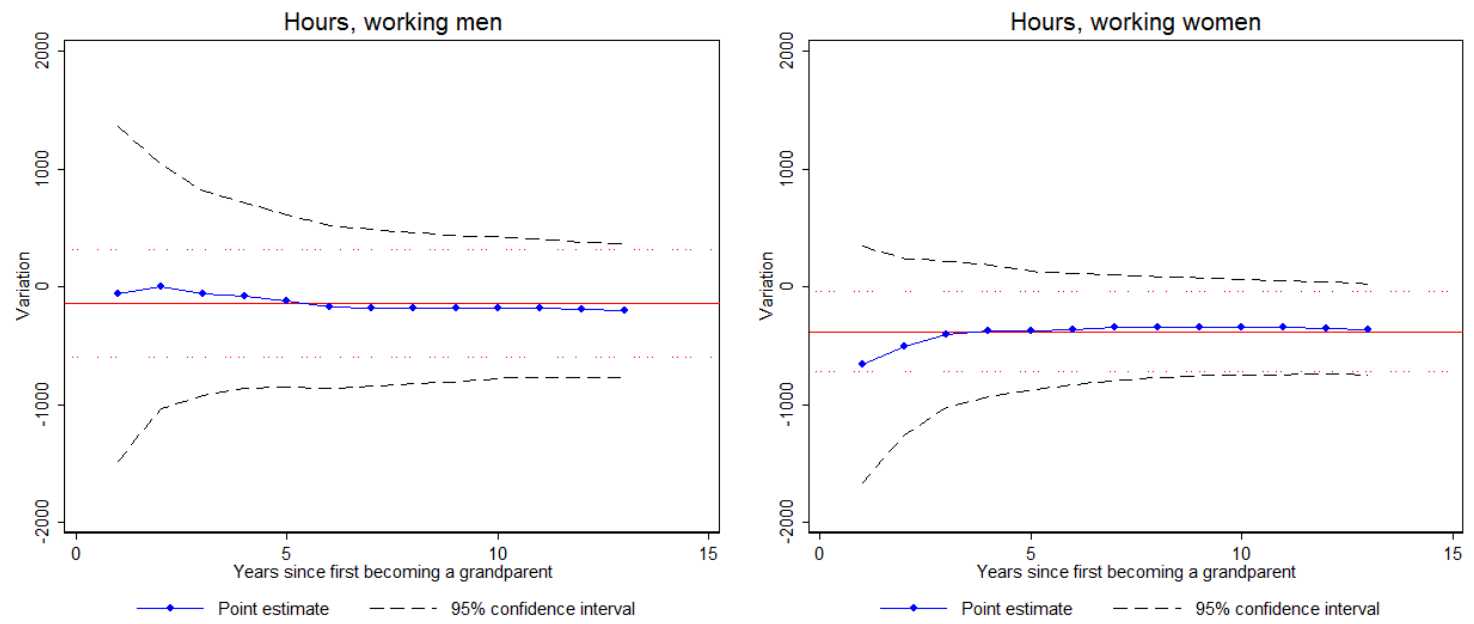

Notes: The figure illustrates IV point estimates of the effect of $g_{i t \ell}$ on hours of working grandparents. The instrument is girlfirst. Only individuals who have been grandparents for less than $\ell$ years are included in the regression. The red, horizontal lines are the point estimates reported in Table 10 and the associated 95\% confidence intervals.

Table 14: IV estimates. Interaction with age

\begin{tabular}{lcccccc}
\hline & $(1)$ & $(2)$ & $(3)$ & $(4)$ & $(5)$ & $(6)$ \\
\cline { 2 - 7 }$g_{i t} \times$ age $_{i t}$ & $h_{i t}$ & $h_{i t}$ & $e_{i t}$ & $e_{i t}$ & $H_{i t}$ & $H_{i t}$ \\
& men & women & men & women & men & women \\
\cline { 2 - 7 }$y 67_{i}$ & -4.0 & -10.1 & 0.002 & 0.000 & 0.9 & -5.7 \\
& $(5.0)$ & $(4.2)$ & $(0.003)$ & $(0.003)$ & $(7.5)$ & $(5.7)$ \\
Constant & 1.3 & -1.2 & 0.001 & 0.001 & 3.1 & 0.7 \\
& $(0.5)$ & $(0.5)$ & $(0.000)$ & $(0.000)$ & $(0.7)$ & $(0.7)$ \\
& 1543.9 & 1318.0 & 0.127 & -0.169 & 235.0 & -243.2 \\
Observations & 37,722 & 48,331 & 44,998 & 71,965 & 44,998 & 71,965 \\
Fixed effects & No & No & No & No & No & No \\
Age dummies & Yes & Yes & Yes & Yes & Yes & Yes \\
Year dummies & Yes & Yes & Yes & Yes & Yes & Yes \\
\hline \hline
\end{tabular}

Notes: 2SLS estimates, PSID core sample, waves 1968-2011, individuals (Seniors, in Section 2) no older than 70 who have at least one child (Junior, in Section 2) who is 14 or older. The dependent variables are, alternately, annual hours of work for pay conditional on being employed (i.e., excluding zero hours, $\left.h_{i t}\right)$, an employment dummy $\left(e_{i t}\right)$, and unconditional annual hours of work for pay (i.e., including zero hours, $H_{i t}$ ); ngchildren $_{i t}$ is the number of grandchildren individual $i$ has in year $t$. The instrument is girl first $t_{i} \times a g e_{i t}$. Covariate $y 67_{i}$ is family income in 1967 and controls for unequal sampling probabilities in a regression framework (Solon et al. (2013)). Robust standard errors in parentheses, clustered at the individual level. 
The coefficients from this regression, at the $25^{\text {th }}$ and $75^{\text {th }}$ quantiles, are reported in Table 15 . This table shows an interesting pattern. While the bulk of the adjustment for employed men, if any, takes place at the top of the distribution-where overtime work is substantial-employed women adjust their labor supply mostly at the bottom of distribution-where part-time and more discontinuous jobs prevail. This pattern suggests that it is working women less attached to the labor market that reduce labor supply in response to the appearance of grandchildren. Instead, those women who hold full time, continuous jobs do not seem to adjust their labor supply much. For working men, on the contrary, if there is any reduction in hours when they become grandparents, this comes from reducing overtime work.

Table 15: IV estimates at $25^{\text {th }}$ and $75^{\text {th }}$ quantiles

\begin{tabular}{lcccc}
\hline & $(1)$ & $(2)$ & $(3)$ & $(4)$ \\
\cline { 2 - 5 } & $h_{i t}$ & $h_{i t}$ & $h_{i t}$ & $h_{i t}$ \\
& men & women & men & women \\
\cline { 2 - 5 }$g_{i t}$ & -6.8 & -837.6 & -192.2 & -75.7 \\
$y 67_{i}$ & -153.6 & 115.2 & 31.1 & -42.3 \\
Constant & 2110.5 & 805.3 & 2518.9 & 114.0 \\
& & & & \\
Observations & 37,722 & 48,331 & 37,722 & 48,331 \\
Quantile & $25^{\text {th }}$ & $25^{\text {th }}$ & $75^{\text {th }}$ & $75^{\text {th }}$ \\
Fixed effects & No & No & No & No \\
Age dummies & Yes & Yes & Yes & Yes \\
Year dummies & Yes & Yes & Yes & Yes \\
\hline \hline
\end{tabular}

Notes: Instrumental variable quantile regression (IVQR) at the $25^{\text {th }}, 50^{\text {th }}$, and $75^{\text {th }}$ quantiles of the distribution of hours conditional on employment. PSID core sample, waves 1968-2011, individuals (Seniors, in Section 2) no older than 70 who have at least one child (Junior, in Section 2) who is 14 or older. The dependent variable is annual hours of work for pay conditional on being employed (i.e., excluding zero hours, $h_{i t}$ ). The instrument is girlfirst, as defined in Eq. 19. Covariate $y 67_{i}$ is family income in 1967 and controls for unequal sampling probabilities in a regression framework (Solon et al. (2013)). Standard errors are not estimated.

\subsection{Ethnicity and education}

Finally, we explore heterogeneity along ethnicity and education. We do so by splitting the sample according to the two main ethnic categories in our sample (White non-Hispanic and Black non-Hispanic) and according to three categories of highest educational attainment (less than high school, high school degree, at least some college). The results are reported in Table 16 and Table 17.

If we focus on the coefficients (standard errors are such that there are no statistically significant difference across the various groups) then we see in these tables that the negative effect on working grandparents is stronger for whites and for intermediate levels of education. These results may sound counterintuitive, but it is important to keep in mind the meaning of these coefficients. They do not mean that white grandparents with intermediate levels of education are doing more child 
Table 16: IV estimates by ethnic group

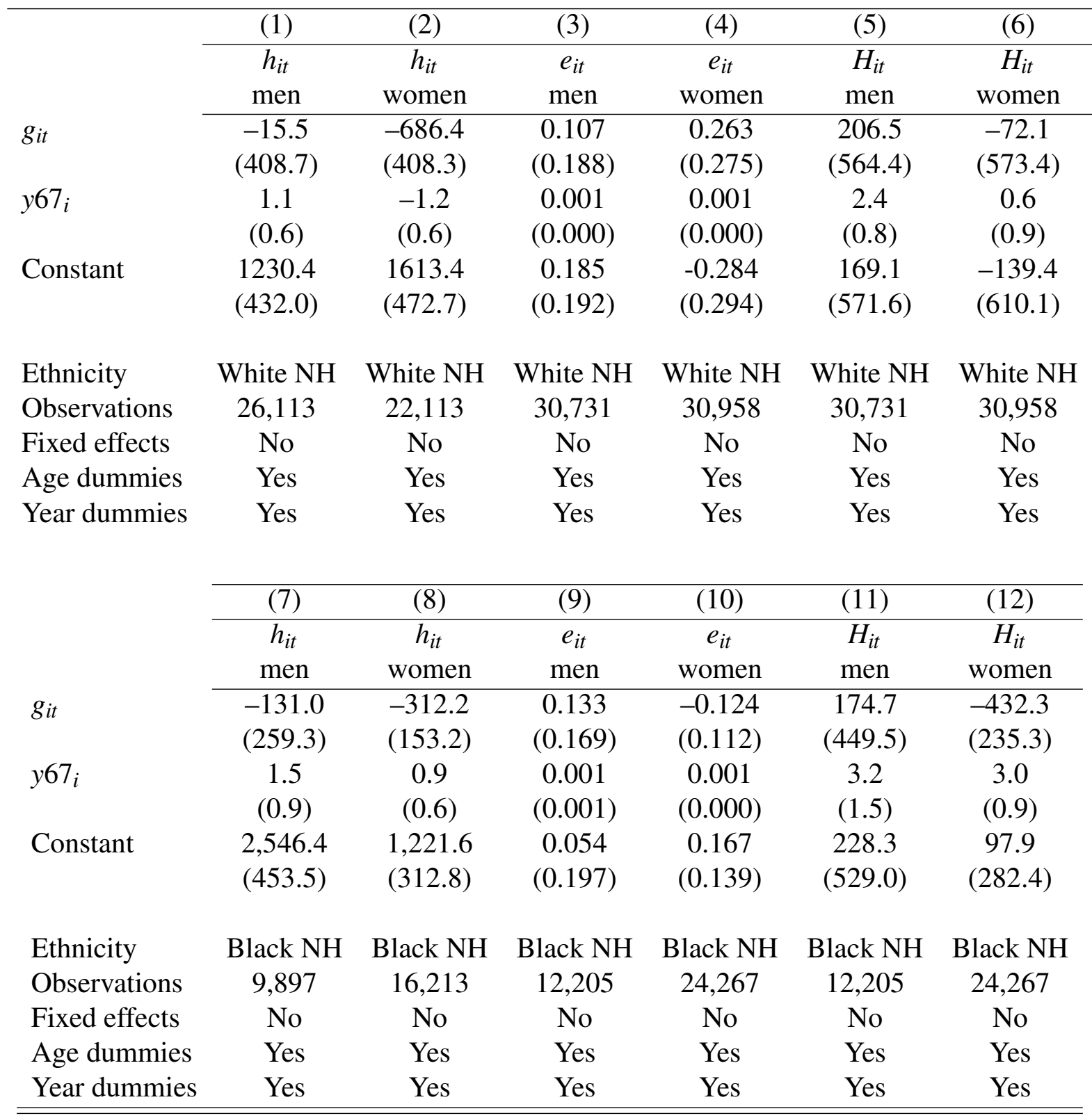

Notes: 2SLS estimates, PSID core sample, waves 1968-2011, individuals (Seniors, in Section 2) no older than 70 who have at least one child (Junior, in Section 2) who is 14 or older. The dependent variables are, alternately, annual hours of work for pay conditional on being employed (i.e., excluding zero hours, $\left.h_{i t}\right)$, an employment dummy $\left(e_{i t}\right)$, and unconditional annual hours of work for pay (i.e., including zero hours, $H_{i t}$ ). Ethnic groups: 'White NH' are individuals reporting white, non-hispanic ethnicity; 'Black NH' are individuals reporting black, non-hispanic ethnicity. The instrument is girlfirst, as defined in Eq. 19. Covariate $y 67_{i}$ is family income in 1967 and controls for unequal sampling probabilities in a regression framework (Solon et al. (2013)). Robust standard errors in parentheses, clustered at the individual level. 
Table 17: IV estimates by education

\begin{tabular}{lcccccc}
\hline & $(1)$ & $(2)$ & $(3)$ & $(4)$ & $(5)$ & $(6)$ \\
\cline { 2 - 7 }$g_{i t}$ & $h_{i t}$ & $h_{i t}$ & $e_{i t}$ & $e_{i t}$ & $H_{i t}$ & $H_{i t}$ \\
& men & women & men & women & men & women \\
\cline { 2 - 7 } Education & 234.5 & -211.5 & 0.103 & -0.009 & 435.4 & -103.6 \\
Observations & $(266.6)$ & $(228.2)$ & $(0.177)$ & $(0.154)$ & $(453.3)$ & $(291.0)$ \\
& Below HS & Below HS & Below HS & Below HS & Below HS & Below HS \\
& 8,441 & 9,751 & 10,880 & 19,373 & 10,880 & 19,373 \\
& & & & & & \\
\cline { 2 - 7 } & $(7)$ & $(8)$ & $(9)$ & $(10)$ & $(11)$ & $(12)$ \\
\cline { 2 - 7 }$g_{i t}$ & $h_{i t}$ & $h_{i t}$ & $e_{i t}$ & $e_{i t}$ & $H_{i t}$ & $H_{i t}$ \\
& men & women & men & women & men & women \\
Education & -704.6 & -529.6 & 0.236 & 0.291 & -80.1 & 24.7 \\
Observations & HS degree & HS degree & HS degree & HS degree & HS degree & HS degree \\
& 13,548 & 21,668 & 16,231 & 31,178 & 16,231 & 31,178 \\
& & & & & & \\
\cline { 2 - 7 } & $(13)$ & $(14)$ & $(15)$ & $(16)$ & $(17)$ & $(18)$ \\
\cline { 2 - 7 } & $h_{i t}$ & $h_{i t}$ & $e_{i t}$ & $e_{i t}$ & $H_{i t}$ & $H_{i t}$ \\
$g_{i t}$ & men & women & men & women & men & women \\
& -80.0 & -377.5 & 0.135 & 0.074 & 151.6 & -93.4 \\
Education & $(556.9)$ & $(563.0)$ & $(0.255)$ & $(0.276)$ & $(822.5)$ & $(658.2)$ \\
Observations & College & College & College & College & College & College \\
& 15,559 & 16,568 & 17,674 & 20,931 & 17,674 & 20,931 \\
Fixed effects & \multicolumn{7}{c}{ No } & No & No & No & No & No \\
Age dummies & Yes & Yes & Yes & Yes & Yes & Yes \\
Year dummies & Yes & Yes & Yes & Yes & Yes & Yes \\
\hline \hline
\end{tabular}

Notes: 2SLS estimates, PSID core sample, waves 1968-2011, individuals (Seniors, in Section 2) no older than 70 who have at least one child (Junior, in Section 2) who is 14 or older. The dependent variables are, alternately, annual hours of work for pay conditional on being employed (i.e., excluding zero hours, $\left.h_{i t}\right)$, an employment dummy $\left(e_{i t}\right)$, and unconditional annual hours of work for pay (i.e., including zero hours, $H_{i t}$ ). Highest educational attainment groups: 'Below HS' are individuals who did not attend or did not complete high school; 'HS degree' are individuals who obtained a high school degree (or equivalent degree) but did not attend college; 'College' are individuals who attended college (regardless of whether they graduated or not). The instrument is girlfirst, as defined in Eq. 19. A constant and covariate $y 67_{i}$ (family income in 1967, to controls for unequal sampling probabilities in a regression framework, Solon et al. (2013)) are included but not reported. Robust standard errors in parentheses, clustered at the individual level. 
care than the rest of the population. They mean that working individuals in this group are reducing their labor supply more than other groups in response to becoming a grandparent. Of course, the baseline levels of employment and hours - as well as the extent to which individuals in different groups reallocate differently leisure and market work when grandchildren appear-matter in this respect. We can gain some intuition into this process by looking at average hours, employment, and time spent taking care of children across such groups.

Table 18 reports these statistics, computed using the PSID and the ATUS, for the population between 40 and 70 years old. This table shows, for instance, that the group that provides more child care in this population-black women-is also the group with the lowest employment rate. When these non-employed women become grandmothers, of course, their time transfer may only come at the expense of other forms of "leisure", not labor supply.

Table 18: Labor supply and child care by ethnicity, gender, and education

\begin{tabular}{lcccccccc}
\hline \multirow{2}{*}{ Group } & \multicolumn{2}{c}{ Work } & \multicolumn{2}{c}{ Primary child care } & \multicolumn{2}{c}{ Secondary child care } & \multicolumn{2}{c}{ Total child care } \\
Black men & Hours & Employed & Min & Frac. $>0$ & Min & Frac. $>0$ & Min & Frac. $>0$ \\
Black women & 2062.4 & 0.745 & 17.1 & 0.155 & 66.7 & 0.179 & 83.8 & 0.237 \\
White men & 1721.2 & 0.641 & 26.5 & 0.234 & 90.0 & 0.243 & 116.5 & 0.320 \\
White women & 2180.7 & 0.829 & 18.7 & 0.178 & 61.9 & 0.188 & 80.6 & 0.249 \\
Less than high school & 1659.3 & 0.678 & 33.1 & 0.249 & 76.3 & 0.215 & 109.4 & 0.297 \\
High school degree & 1823.4 & 0.589 & 23.1 & 0.182 & 80.9 & 0.210 & 104 & 0.279 \\
At least come college & 1852.9 & 0.708 & 21.4 & 0.188 & 67.9 & 0.199 & 89.3 & 0.262 \\
Employed & 1960.3 & 0.817 & 29.7 & 0.246 & 79.5 & 0.231 & 109.2 & 0.308 \\
Not employed & 1900.6 & 1 & 23.6 & 0.225 & 75.0 & 0.229 & 98.6 & 0.303 \\
\hline \hline
\end{tabular}

Notes: The table reports, for various demographic and socioeconomic groups and for individuals between 40 and 70 years old, labor supply measures from the PSID (1967-2010) and child care measures from the ATUS (2008-2012). Sampling weights are applied. The labor supply measures are hours conditional on employment and the fraction employed. The child care measures are average daily minutes (including zeros) of primary and secondary child care (caring for and helping, and activities related to children's education and health, and associated travel time), and the fraction reporting a strictly positive amount of minutes. The last column is the sum of average of the products of minutes and such fraction across primary and secondary child care time. Both children living in the household and those living in another household are considered. 'White' and 'Black' do not include Hispanic origin. The education labels refer to highest educational attainment. 'Less than HS' are individuals who did not attend or did not complete high school; 'HS degree' are individuals who obtained a high school degree (or equivalent degree) but did not attend college; 'College' are individuals who attended college, regardless of whether they graduated or not. 


\section{Conclusions}

While there is a large literature on the labor supply effect of becoming a parent, time use data show that many older workers make large time transfers in the form of grandparent-provided child care. In this paper we have investigated the consequences of such transfers for senior workers' labor supply. Estimation is hampered by the fact that even though the decision to have a child is made by the parents, the knowledge of grandparents' willingness to contribute hours, money, or both toward child care may have influences on the decision of the parent. Therefore, we have employed instruments to overcome the ensuing endogeneity of the grandparent status.

The estimation provides evidence on the causal effect of becoming a grandparent on labor supply late in the working life. The baseline evidence indicates that working grandmothers in the U.S. reduce their labor supply by at least 190 hours every year relative to their counterparts who are not grandmothers. For men the number is lower, about 70 hours per year, but with a large standard error and a possible upward bias which suggests much caution.

We have also found that the reduction in hours for grandmothers occurs towards the bottom of the hours distribution, is larger in the first year or two of becoming a grandmother, and falls as the grandchild ages. For men, the effect originates towards the top of the distribution, is not as pronounced, and occurs somewhat later than that for grandmothers. Moreover, distance from the grandchild matters. For women, the reduction in hours of work increases with proximity to grandchildren, roughly an additional 100 hours if living in the same county and 130 if living in the same census tract. However, it appears that for men, the entire effect is driven by those living far away from the grandchildren, but again with large standard errors.

How large is the baseline effect we have identified? We have reported in Section 1 that conditional on strictly positive transfers, women and men spend on average 820 and 440 hours, after age 50 , taking care of their grandchildren. Our baseline lower bounds account for about 23\% and 16\% of these time transfers, respectively. This is the answer to the question we ask in the Introduction, namely how much grandparenting comes at the expense of other forms of "leisure" and how much comes at the expense of market labor supply?

Furthermore, we can use our estimates to perform a back-of-the-envelope calculation of the role of grandparenting in contributing to the large reductions in senior workers' labor supply along the intensive margin we have documented in Rupert and Zanella (2012). In that paper we show that in the PSID working women reduce labor supply by about 400 hours between the age of 50 and 64. The corresponding reduction for men is much larger, about 720 hours. Because about $85 \%$ of individuals in our sample become parents and because, of these, about $90 \%$ become grandparents at some point in life, then this channel accounts for $0.85 \times 0.9 \times 190 / 400 \simeq 36 \%$ for women and $0.85 \times 0.9 \times 70 / 720 \simeq 8 \%$ for men. These magnitudes are non-negligible, especially for women, and point at the importance of the question we have investigated in this paper. Increasing life expectancy in advanced countries offers parents an inexpensive, flexible, and reliable source of child care-grandparents. However, a prolonged and healthy mature age also requires a longer attachment to the labor market during the late stages of the life cycle. There is a possible trade-off between these two desiderata. 


\section{References}

Aguero, J. M., Marks, M. S., 2008, Motherhood and female labor force participation: Evidence from infertility shocks, American Economic Review 98, 500-504.

Angrist, J. D., Evans, W. N., 1998, Children and their parents' labor supply: Evidence from exogenous variation in family size, American Economic Review 88, 450-77.

Bailey, M. J., 2006, More power to the pill: The impact of contraceptive freedom on women's life cycle labor supply, The Quarterly Journal of Economics 121, 289-320.

Becker, G. S., 1965, A theory of the allocation of time, The Economic Journal 75, 493-517.

Bedard, K., Deschenes, O., 2005, Sex preferences, marital dissolution, and the economic status of women, Journal of Human Resources 40, 411-434.

Bloom, D., Canning, D., Fink, G., Finlay, J., 2009, Fertility, female labor force participation, and the demographic dividend, Journal of Economic Growth 14, 79-101.

Bronars, S. G., Grogger, J., 1994, The economic consequences of unwed motherhood: Using twin births as a natural experiment, American Economic Review 84, 1141-56.

Cardia, E., Ng, S., 2003, Intergenerational time transfers and childcare, Review of Economic Dynamics 6, 431-454.

Chernozhukov, V., Hansen, C., 2006, Instrumental quantile regression inference for structural and treatment effect models, Journal of Econometrics 132, 491-525.

Choi, H., 2009, Proximity to mother: Cross-sectional and life-course aspects, Mimeo .

Chun, H., Oh, J., 2002, An instrumental variable estimate of the effect of fertility on the labour force participation of married women, Applied Economics Letters 9, 631-634.

Compton, J., Pollak, R., 2013, Proximity and coresidence of adult children and their parents in the united states: Description and correlates, IZA Discussion Papers 7431, Institute for the Study of Labor (IZA).

Compton, J., Pollak, R. A., 2014, Family proximity, childcare, and womens labor force attachment, Journal of Urban Economics 79, 72 - 90, spatial Dimensions of Labor Markets.

Cruces, G., Galiani, S., 2007, Fertility and female labor supply in latin america: New causal evidence, Labour Economics 14, 565-573.

Dahl, G. B., Moretti, E., 2008, The demand for sons, Review of Economic Studies 75, 1085-1120.

Dimova, R., Wolff, F.-C., 2011, Do downward private transfers enhance maternal labor supply? evidence from around europe, Journal of Population Economics 24, 911-933.

Fiorito, R., Zanella, G., 2012, The anatomy of the aggregate labor supply elasticity, Review of Economic Dynamics 15, 171-187. 
Heckman, J. J., 1974, Effects of child-care programs on women's work effort, Journal of Political Economy 82, S136-S163.

Ho, C., 2014, Grandchild care, intergenerational transfers, and grandparents' labor supply, Review of Economics of the Household, forthcoming .

Ichino, A., Lindstrom, E.-A., Viviano, E., 2013, Hidden consequences of a first-born boy for mothers, Mimeo .

Jacobsen, J. P., Pearce, J. W., Rosenbloom, J. L., 1999, The effects of childbearing on married women's labor supply and earnings: Using twin births as a natural experiment, Journal of Human Resources 34, 449-474.

Johnson, W. R., Skinner, J., 1986, Labor supply and marital separation, American Economic Review 76, 455-69.

Kwak, D. W., 2010, Implementation of instrumental variable quantile regression (ivqr) methods, Mimeo .

Lei, X. S., 2008, Grandchild care, financial transfers, and grandma's labor market decisions, Mimeo .

Lundberg, S., 2005, Sons, daughters, and parental behaviour, Oxford Review of Economic Policy $21,340-356$.

Morgan, S. P., Lye, D. N., Condran, G. A., 1988, Sons, daughters, and the risk of marital disruption, American Journal of Sociology 94, 110-129.

Posadas, J., Vidal-Fernandez, M., 2012, Grandparents' childcare and female labor force participation, IZA Discussion Paper No. 6398.

Reinkowski, J., 2013, Should we care that they care? grandchild care and its impact on grandparent health, Ifo Working Paper Series Ifo Working Paper No. 165.

Rondinelli, C., Zizza, R., 2010, (non)persistent effects of fertility on female labour supply, Economic Working Papers 783, Bank of Italy, Economic Research and International Relations Area.

Rosenzweig, M. R., Wolpin, K. I., 1980, Testing the quantity-quality fertility model: The use of twins as a natural experiment, Econometrica 48, 227-40.

Rupert, P., Zanella, G., 2012, Revisiting wage, earnings, and hours profiles, Mimeo .

Solon, G., Haider, S. J., Wooldridge, J., 2013, What are we weighting for?, NBER Working Papers 18859, National Bureau of Economic Research, Inc.

Zamarro, G., 2011, Family labor participation and child care decisions: The role of grannies, Working Papers 833, RAND Corporation Publications Department. 


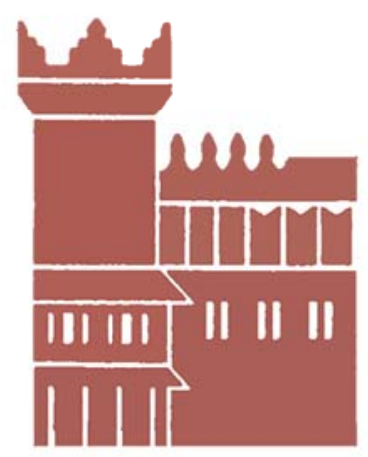

Alma Mater Studiorum - Università di Bologna DEPARTMENT OF ECONOMICS

Strada Maggiore 45

40125 Bologna - Italy

Tel. +39051 2092604

Fax +390512092664

http://www.dse.unibo.it 